\title{
The structure of the haze plume over the Indian Ocean during INDOEX: tracer simulations and LIDAR observations
}

\author{
G. Forêt ${ }^{1}$, C. Flamant $^{2}$, S. Cautenet ${ }^{1}$, J. Pelon ${ }^{2}$, F. Minvielle ${ }^{1}$, M. Taghavi ${ }^{1}$, and P. Chazette ${ }^{3}$ \\ ${ }^{1}$ Laboratoire de Météorologie Physique, Université Blaise Pascal, Aubière, France \\ ${ }^{2}$ Institut Pierre-Simon Laplace/Service d'Aéronomie, Université Pierre et Marie Curie, Paris, France \\ ${ }^{3}$ Institut Pierre-Simon Laplace/Laboratoire des Sciences du Climat et de l'Environnement, Centre de l'Energie Atomique, \\ Saclay, France
}

Received: 4 January 2005 - Published in Atmos. Chem. Phys. Discuss.: 24 May 2005

Revised: 21 November 2005 - Accepted: 22 December 2005 - Published: 22 March 2006

\begin{abstract}
Three-dimensional, nested tracer simulations of a pollution plume originating from the Indian sub-continent over the Indian Ocean, in the framework of the Indian Ocean Experiment (INDOEX), between 5 and 9 March 1999, were performed with the Regional Atmospheric Modeling System (RAMS), to provide insight into the transport patterns of the pollutants, as well as to investigate the dynamical mechanisms controlling the vertical structure of the plume and its evolution in the vicinity of the Maldives Islands. Airborne and ground-based LIDAR observations of the structure of the haze plume made on 7 March 1999 were used to assess the quality of the simulations, as well as the impact of grid resolution on the vertical structure of the simulated plume. It is shown that, over the Arabian Sea, in the vicinity of the Maldives Islands, the pollutants composing the plume observed by the airborne LIDAR essentially originated from the city of Madras and that the vertical structure of the plume was controlled by the diurnal cycle of the continental boundary layer depth. A combination of tracer simulations and remote sensing observations (airborne LIDAR, ship-borne photometer, ground-based LIDAR in Goa) was used to analyse the diurnal evolution of the haze plume over the sea. We find evidence that the sea breeze circulation and orographic lifting taking place in the southern part of the Indian sub-continent during the daytime play a crucial role in the modulation of the continental boundary layer depth, and in turn, the haze plume depth. The eastward shift of the subtropical high from central India to the Bay of Bengal after 6 March lead to an increase in the tracer concentrations simulated over the Arabian Sea, in the region of intensive observations north of the Maldives, as transport pathways form Hyderabad and Madras were modified significantly. The nesting of a high horizontal resolution
\end{abstract}

Correspondence to: G. Forêt

(foret@lisa.univ-paris12.fr) domain $(5 \mathrm{~km}$, with 39 vertical levels below $4000 \mathrm{~m}$ above mean seal level) allows for a better representation of local dynamics, the circulation of sea and mountains breezes, and therefore a noticeable improvement in the representation of the pollutants' plume in the simulation.

\section{Introduction}

Aerosols are an important factor of climate change due to their radiative impact on the Earth's energy budget and the substantial increase in their global mean burden from preindustrial times to the present day. Except in remote oceanic locations, the atmospheric aerosol burden is generally composed of a wide variety of natural aerosols (e.g. mineral dust, sea salts) and anthropogenic aerosols (e.g. sulfate, nitrate, carbonaceous aerosols). All aerosols have the ability to intercept short and long wave radiation and reflect back incident solar radiation into space (direct effect). Some aerosols act as cloud condensation nuclei and thereby determine the cloud droplet number concentration and efficiency. They modify cloud optical properties by increasing cloud albedo (first indirect effect) or cloud lifetime and precipitation (second indirect effect). Both effects result in a cooling, which partially offsets the greenhouse gas warming. Aerosols absorbing solar radiation may be conducive to warming in the lower atmosphere and induce (locally) a reduction of the cloud cover (semi-direct effect).

The magnitude of all these competing effects is difficult to assess because of (i) the highly variable three-dimensional distribution of aerosols with time, due to fluctuations in source strength and location; (ii) the paramount diversity of aerosols with highly variable physico-chemical properties, which interact differently with hydrological cycle. For

Published by Copernicus GmbH on behalf of the European Geosciences Union. 
instance, using a global circulation model, Lohmann and Feichter (2001) compared the magnitude of all these competing effects and found that, even though the indirect effects dominated globally, the semi-direct effect could be important locally.

Several experiments, such as the Transport of Aerosols and Radiative Forcing Experiment (TARFOX) (Russell et al., 1999), the second Aerosol Characterization Experiment (ACE-2) (Raes et al., 2000), the Indian Ocean Experiment (INDOEX) (Ramanathan et al., 2001) and the Asian Aerosol Characterization Experiment (ACE-Asia) (Huebert et al., 2003), have been conducted to reduce the uncertainties associated with the diverse aerosol effects. In the framework of these experiments, an impressive amount of ground-based, ship-borne and airborne in situ, as well as remote sensing instruments, have been deployed to better understand and to characterize the aerosol optical and radiative properties in the regions of interest. Such experiments also aimed at improving the quality of satellite aerosol retrievals and contribute to the assessment of aerosol radiative forcing at the regional scale.

Models are valuable tools to bridge the gap between in-situ and satellite measurements in such integrated analyses. They offer large spatial and temporal coverage, which provides opportunities to study the formation of pollution plumes, the transport patterns of aerosols, as well as their radiative impact based on their composition. Nevertheless, such modeling studies are still not fully reliable due to uncertainties associated with the characterization of aerosols: emission, deposition and transport, as well as aerosol microphysics, composition and optical properties.

Such studies are generally undertaken in the vicinity of coastal areas since, to this day, aerosol radiative forcing cannot be assessed over continents. In addition, coastal zones are known to have an important role on pollutants' redistribution at regional or even on a continental scale (Lyons et al., 1995; Angevine et al., 1996). As a consequence, the complex dynamics occurring in these regions (including the diurnal cycle of convection over land) needs to be well simulated. This is crucial as the knowledge of the vertical distribution of aerosols within a pollution plume is key for properly assessing the associated radiative forcing, as well as for air quality concerns. As underlined by Lyons et al. (1995), mesoscale meteorological and transport models are approriate tools for such studies and the rapid improvement of computational skills now allows the handling of complex processes at fine horizontal and vertical scales, which is of great importance for pollutants transports (Wang et al., 2004).

In the framework of the INDOEX experiment, Ramanathan et al. (2001) and Reddy et al. (2004) have shown that the pollution plume expelled from the continent over the Indian Ocean during the winter had an important radiative impact at the regional scale. It has also been shown that the pollution plume generally resulted from the mixing of air masses transported over long distances and whose aerosol characteristics were quite diverse (Rajeev et al., 2000; Lobert et al., 2002). Minvielle et al. (2004a, b) have shown that the regional transport model could account for the long range transport and horizontal mixing. However, they could not reproduce the complex vertical structure of the pollution plume over the ocean because of the coarse resolution. On the other hand, the effects of local circulations associated with the Western Ghats range on the vertical distribution of pollutants was investigated with a short 6-km resolution simulation by Léon et al. (2001) between the cities Goa and Dharwhar (separated by approximately $150 \mathrm{~km}$ ). However, their simulation was not designed to analyze the interactions between the long range transport and the small-scale dynamics near the Arabian Sea coastline. Consequently, the objective of the present study was to conduct a series of simulations with increased resolution, to better represent the regional dynamics and to be able to assess the impact of small-scale dynamics on the aerosol transport at the scale of the Indian sub-continent. To do so, nested, two-way simulations have been designed to be able to focus on specific areas with complex dynamics having an impact on pollutants' redistributions at larger scales (i.e. formations of layered plumes). This has been made possible because of a new model version with enhanced computation efficiency (parallel version of the RAMS model).

In this paper, we analyse the three-dimensional (3-D) structure of the Indo-Asian pollution plume transported from the Indian sub-continent in early March of 1999 over the Indian Ocean using a combination of mesoscale simulations (made with the model Regional Atmospheric Modeling System -RAMS) and airborne LIDAR measurements (LIDARs being one of the few instruments able to provide high resolution vertical distribution of aerosols). LIDAR observations were acquired in the course of the INDOEX Intensive Field Phase (IFP), held during the 1999 winter monsoon period. We focus our study on LIDAR measurements made on 7 March 1999 during a Mystère-20 (M-20) mission north of the Maldives Islands (Pelon et al., 2002). The region investigated is shown in Fig. 1.

The focus of this paper is (i) to assess whether the transport patterns leading to the simulated 3-D structure of the plume made with the RAMS over the Indian Ocean in the vicinity of the Maldives Islands are consistent with observations made by LIDAR on board the M20, and (ii) to better understand the role of local circulations in the transport of trace constituents on a regional scale. A two-way grid nesting approach has been chosen to address these issues. At this point we have only considered passive tracers as a proxy for anthropogenic aerosols. We also have not considered the entire Indian sub-continent as a source region, but rather have selected 4 cities (Bombay, Madras, Hyderabad and Calcutta) as the major emission sources. This exercise is nearly impossible to do based on realistic emissions of "real aerosols" because sources are numerous and aerosols cannot be tagged to their sources. Our objective is to determine the origin of the aerosol composing the plume observed by LIDAR on 7 
March 1999 (Pelon et al., 2002) and to assess whether the transport patterns leading to the simulated vertical structure of the plume are consistent with observations.

In Sect. 2, we present briefly the INDOEX experiment, the synoptic conditions during the first week of March 1999 as well as the observations made on 7 March 1999, during the IFP. In Sect. 3, the RAMS model and the simulation designed for INDOEX are presented. In Sect. 4, using the tracer simulations, we discuss the origin of the aerosol composing the plume near the Maldives Islands and the vertical structure of the plume. We also discuss the diurnal evolution of the structure of the monsoon plume, as well as its propagation over the Indian Ocean, in light of simulations, as well as ship-borne and ground-based remote sensing observations. Finally, we discuss the sensitivity of the plume structure to the grid resolution, as well as the vertical structure of the plume simulated with RAMS. In Sect. 5, we summarize and conclude.

\section{The Indian Ocean experiment}

\subsection{Background}

The INDOEX IFP (February-March 1999) highlighted the formation of an important pollutant haze over India, Bay of Bengal and Arabian Sea, spreading as far south as the Intertropical Convergence Zone (ITCZ) (Lelieveld et al., 2001) during the winter monsoon. The main mechanisms responsible for the formation of this huge plume have been described in Ramanathan et al. (2001) and Verver et al. (2001) and are only briefly recalled here.

India is an important source region of anthropogenic aerosols (Lelieveld et al., 2001). Gaseous pollution emissions in India are essentially related to domestic biofuel and agricultural waste burning (Streets and Waldhoff, 1999; Sinha et al., 1998; Mahapatra and Michel, 1999). Sources are located both in the large cities of India, as well as throughout the country. During the winter monsoon period (January to April), anticyclonic conditions dominate the Indian continent, allowing for the accumulation of pollutants caused by suppressed precipitations and upward dispersion. At the same time, the prevailing northerly/northeasterly trade winds from the Asian continent transport the highly polluted air masses over the Indian Ocean to the ITCZ. Two separate layers within the trade-wind layer (i.e. the marine ABL and the "haze layer" from the continent) are generally observed over the ocean, together with a strong subsidence aloft. Under such meteorological conditions, pollutants may undergo long range transport and can be spread over the Arabian Sea, Gulf of Bengal and Indian Ocean.

During the second half of the INDOEX IFP (mid Febuary to late March), a high pressure area was located over the northwestern part of the Indian continent and a low pressure system was over western Indonesia (Rasch et al., 2001). A

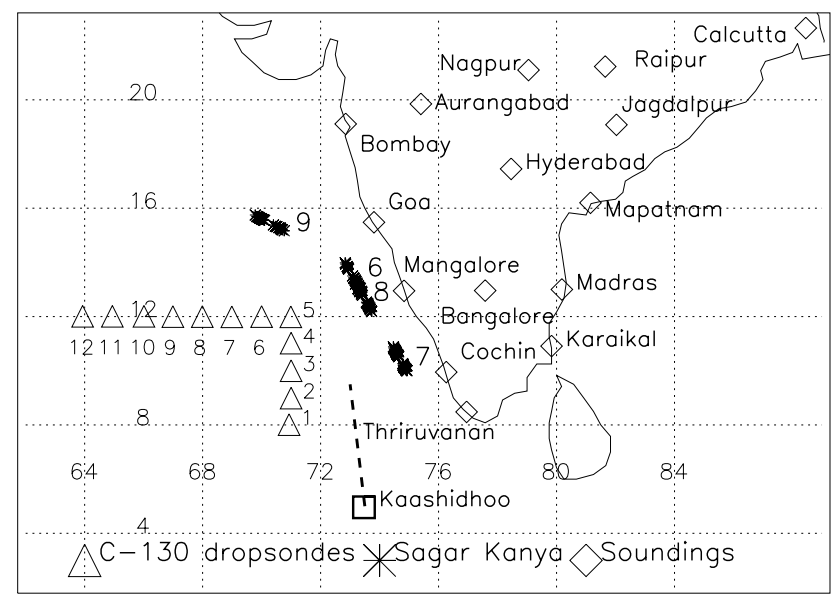

Fig. 1. Location of the sounding stations network over continental India (lozenges), as well as Kaashidhoo, Maldives (square). The Mystère 20 flight track, along which LIDAR data shown in Fig. 2 were acquired, is shown by the thick dashed line. The position of the dropsondes released from the Met Office C-130 Hercules aircraft on 7 March 1999 over the Arabian Sea are shown as triangles. The position of the Research Vessel Sagar Kanya (R/V SK) between 6 and 9 March 1999 (number corresponding to the day of March) is shown as asterisks.

study of tagged radon transport (Rasch et al., 2001) demonstrated that, in the region of interest for this study - i.e. the part of the Indian Ocean between the Maldives and the Indian sub-continent (delimited by the smallest box in Fig. 1), synoptic conditions favored long-range transport of pollutants from India exclusively for the beginning of March. The main circulation patterns for this period are displayed in Fig. 4.

The dry monsoon initiated the buildup of the haze over the Indian sub-continent, as shown by the seasonal cycle of the Aerosol Optical Depth (AOD) and an aerosol burden over the western coast of India, observed at Goa and Dharwad (Léon et al., 2001). During the INDOEX IFP, ground-based, shipborne and airborne measurements revealed very high concentrations of aerosols and trace gases over the Arabian Sea, with the pollution levels sometimes reaching those observed in the North America suburbs (Lelieveld et al., 2001). The Maldives Islands are the focus point of air mass from different origins in the Marine Atmospheric Boundary Layer (MABL) and aloft during the winter monsoon (e.g. Reiner et al., 2001; Pelon et al., 2002). Meteosat 5 exhibited aerosol optical depths as high as 0.5 in the vicinity of the Maldives during the first half of March (Léon et al., 2001; Pelon et al., 2002). According to Ramanathan et al. (2001), emissions responsible for those high levels of pollution are mainly from anthropogenic origins $(80 \% \pm 10 \%)$. 


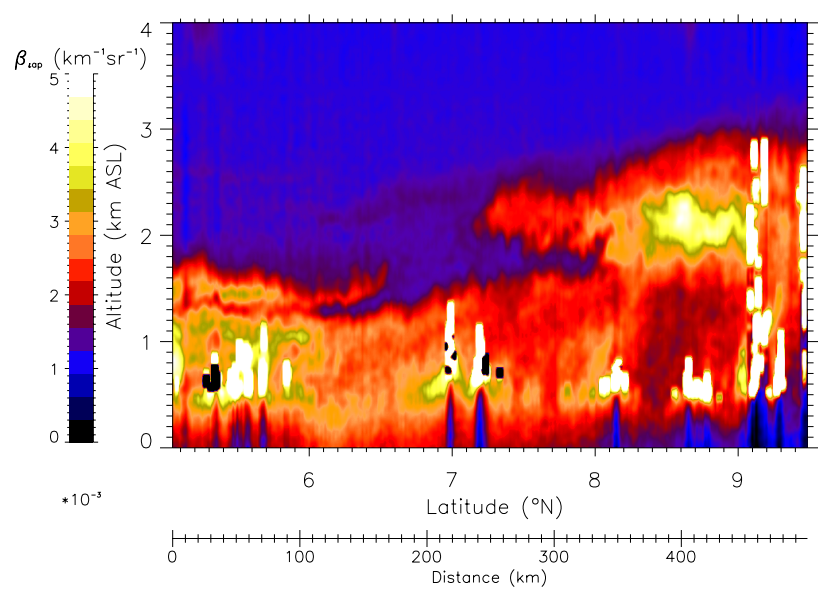

Fig. 2. Lidar derived attenuated backscatter coefficient obtained at $532 \mathrm{~nm}$ by the Leandre 1 Lidar on 7 March 1999 (03:4404:39 UTC).

\subsection{Synoptic conditions during the first week of March} 1999

Two near-equatorial convergence zones were observed in the Indian Ocean region: one along $2^{\circ}-5^{\circ} \mathrm{N}$ and one around the equator, which was more intense (Verver et al., 2001). The northern convergence zone was more active during February while the southern convergence zone became dominant in March, thereby favoring cross-equatorial flow and pollution transport from the Northern Hemisphere into the Southern Hemisphere.

On 7 March 1999, a northerly flow dominated over most of the Arabian Sea while offshore flow prevailed over coastal northeast India. The air parcels then curled anticyclonically over the western Bay of Bengal around a weak high pressure (Fig. 4). No significant precipitations were observed on the southern tip of India and southern Arabian Sea for the beginning of March.

\subsection{INDOEX-related operations on 7 March 1999}

Besides the M-20, many other platforms have been specifically deployed in the framework of the INDOEX IFP, operated on 7 March 1999. The Met Office C-130 Hercules aircraft flew to the west of the M-20 track, while the Indian Research Vessel Sagar Kanya (R/V SK) cruised along the western India coast line (see Fig. 1). In addition, a groundbased backscatter lidar was also operating at the site of Goa (Léon et al., 2002; Chazette, 2003).

On 7 March 1999, the Met Office C-130 released 12 dropsondes, and 12 soundings were also available. The position of the dropsondes and balloon releases are shown in Fig. 1. These shall be used to depict the thermodynamics of the monsoon layer over the Arabian Sea. Also shown in Fig. 1 are the locations of fifteen sounding stations of the dense Indian network, as data from the 00:00 and 12:00 UTC (UTC=LT-5.5 h) soundings shall be used (when available) for RAMS simulations validation purposes. Finally, airborne and ground-based backscatter lidar measurements made on board the M-20 and at Goa, respectively, as well as shipborne Sun-photometer measurements made on the R/V SK, shall be used to analyse the vertical structure and the diurnal evolution of the monsoon layer.

\subsection{Airborne backscatter LIDAR measurements on 7 March 1999}

The LIDAR observations of interest were acquired along one leg of the 7 March 1999 mission (the leg is referred to as FT1 in the following). FT1 was designed to be roughly oriented north-south. The position of this leg, along which model fields have been extracted to compare with LIDAR measurements, is shown in Fig. 1. LIDAR observations between 03:44 and 04:39 UTC (09:14-10:09 LT) are displayed in Fig. 2 in the form of the attenuated backscatter coefficient (ABC) (Pelon et al., 2002). Note that Fig. 2 has been previously published as Fig. 5 in Pelon et al. (2002) and as Fig. 8 in Minvielle et al. (2004a). This figure appears courtesy of the American Geophysical Union and Elsevier Ltd. The $\mathrm{ABC}$, the product of the total (molecules and particles) backscatter coefficient of a given atmospheric layer and the two-way transmission between the aircraft and that layer, can be used to depict the horizontal and vertical structure of the aerosol plume over the Indian Ocean. The decrease in ABC near the surface, north of $8^{\circ} \mathrm{N}$ or in the presence of clouds at the top of the MABL, is related to lower two-way transmission values above these regions (i.e. aerosol or cloud scattering).

On this day, the vertical structure of the monsoon consisted of two layers: the MABL and the haze plume aloft. As illustrated in Angevine et al. (1996), such vertical structure is characteristic of coastal areas where the MABL is topped by a continental polluted layer when continental winds are oriented toward the sea. The cumulus clouds (characterized by $A B C$ values larger than $5 \mathrm{~km}^{-1} \mathrm{sr}^{-1}$ ) were observed at the top of the MABL, as well as embedded in the land plume. Such clouds may be considered as mixing elements between the MABL and the haze layer. These clouds eventually feed deeper clouds at the ITCZ (Manghnani et al., 2000). The depth of the MABL was relatively constant and varied between 400 and $500 \mathrm{~m}$ along the leg. On the other hand, the depth of the land plume exhibited larger fluctuations as a function of latitude. On 7 March, LIDAR observations of the haze plume above the MABL evidenced 3 regions (Fig. 2):

- a deep plume region: the land plume was observed to be deepest north of $8^{\circ} \mathrm{N}$. The height of the top of the land plume was located at $2.7-3 \mathrm{~km}$ above mean sea level (msl). In this region, the height of the land plume top did vary by as much as $300 \mathrm{~m}$, 
- a shallow plume region: the land plume was observed to be most shallow south of $7^{\circ} \mathrm{N}$. The height of the land plume top varied between $1.4-$ and $1.8-\mathrm{km}$ msl,

- a transition region: between $8^{\circ} \mathrm{N}$ and $7^{\circ} \mathrm{N}$, the land plume top height decreased drastically with latitude from $3-\mathrm{km}$ msl to $1.4-\mathrm{km}$ msl.

According to back trajectory analyses performed by Pelon et al. (2002; see their Figs. 2 and 3), the air masses composing the elevated plume south of $7^{\circ} \mathrm{N}$ were coming from the Gulf of Bengal, whereas the air masses composing the deeper part of the plume (north of $8^{\circ} \mathrm{N}$ ) were coming from the Indian sub-continent.

In Fig. 3a, we have plotted sequentially the potential temperature profiles obtained from the twelve dropsondes released between 05:19 and 07:34 UTC on 7 March 1999 (i.e. north of $8^{\circ} \mathrm{N}$, in the region where the plume was observed to be the deepest). Except for the first one, profiles are being offet by $+5 \mathrm{~K}$ with respect to the previous one. A marked potential temperature gradient is visible at an altitude varying between 2.9 and $3.3 \mathrm{~km}$ a.s.l. over the Arabian Sea (Fig. 3a), which corresponds to the depth of the aerosol plume observed by LIDAR. Back trajectories computed using the NOAA HYSPLIT4 (National Oceanic and Atmospheric Administration Hybrid Single-Particle Lagrangian Integrated Trajectory) Model (Draxler and Hess, 1998) revealed that the air mass sampled with the dropsondes (below 4-km msl) was originating from the Indian sub-continent (not shown). The temperature inversion was observed to be the highest in altitude for the profile closest to the coast (i.e. Profile 5). Along the east-west oriented leg, there was evidence of subsidence, as illustrated by the general trend of the elevated temperature inversion to be lower and the associated potential temperature gradient to increase away from the coast. The depth of the MABL along the south-north oriented dropsonde leg (Profiles 1-5) was also found to be in good agreement with LIDAR observations. The MABL was deepest at the beginning of the east-west oriented leg (Profiles 6-8), its top reaching $1 \mathrm{~km}$ msl. The weekly Reynolds Sea Surface Temperature (SST) analyis available from the NCEP NOMADS Meteorological data server (http://nomad2.ncep.noaa.gov/ncep_data/) for the week of the 6-11 March 1999 evidences the existence of a SST gradient, on the order of $2^{\circ} \mathrm{C}$, at $12^{\circ} \mathrm{N}$ between $64^{\circ} \mathrm{E}$ and $72^{\circ} \mathrm{E}$ (i.e. along the track where the $\mathrm{C} 130$ released the dropsondes 5 through 12). Hence, both the subsidence over the ocean and the SST gradient are likely to explain the westward decrease in MABL height. The MABL was observed to be well mixed on all profiles. The upper half of the haze layer was also found to be well mixed, at least on the eastwest oriented leg.

South of $6^{\circ} \mathrm{N}$, the LIDAR-derived MABL and land plume height top were found to be in agreement with the two temperature inversions evidenced in the 06:11 UTC sounding made in Kashidhoo, Maldives (Fig. 3b). The MABL was
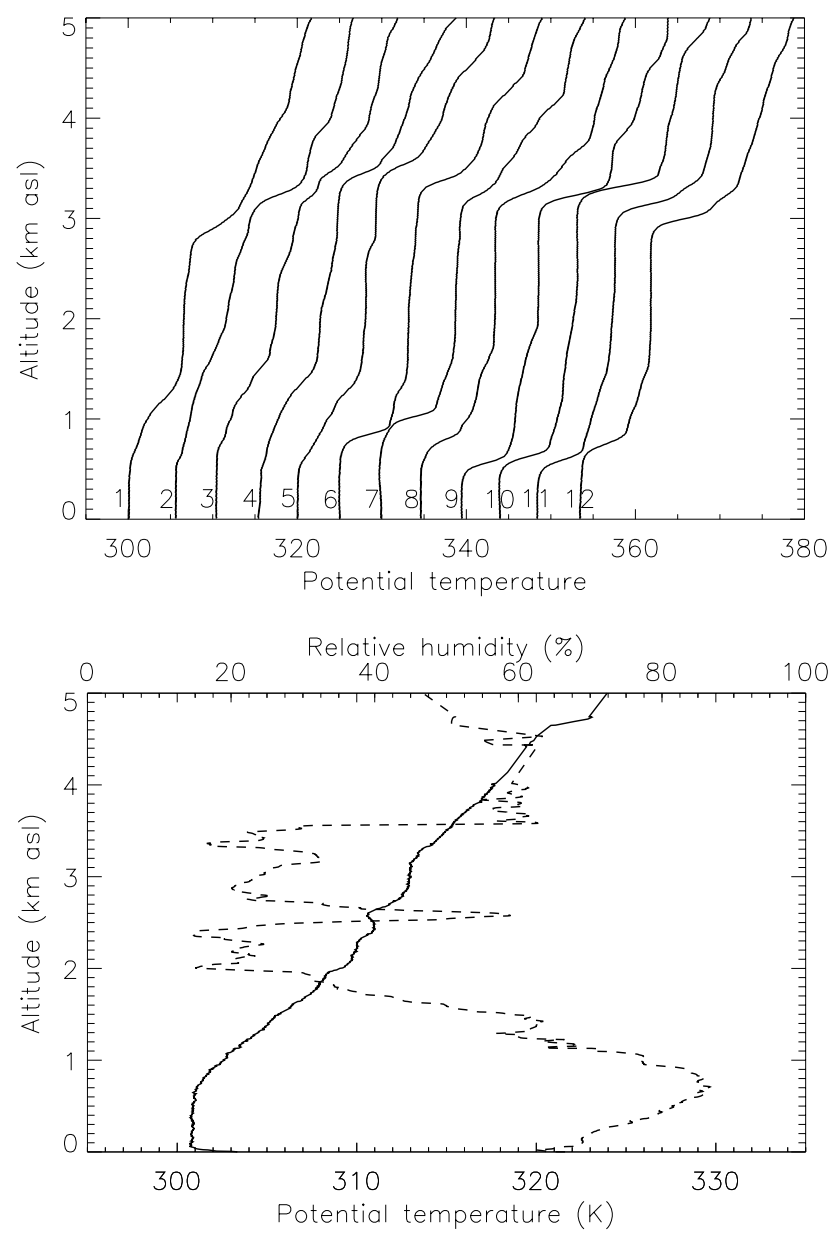

Fig. 3. (a) Potential temperature profiles obtained from dropsondes released from the Met Office C-130 Hercules aircraft on 7 March 1999 over the Arabian Sea between 05:19 and 07:34 UTC. (b) Potential temperature (solid line) and relative humidity (dotted line) profiles obtained with the 06:11 UTC balloon sounding launched in Kaashidhoo, Maldives.

observed to be slightly deeper $(700 \mathrm{~m})$ than the one observed by LIDAR. This is believed to be caused by the influence of the land and related surface heating (recall that the sounding was made $3 \mathrm{~h}$ after the M20 overpass of Kashidhoo). Above the MABL, the lapse rate is about $5 \mathrm{~K} \mathrm{~km}^{-1}$ and the relative humidity decreases drastically from $90 \%$ to $20 \%$. The base of the dry layer was observed at about 2-km msl, an altitude where the lapse rate increased significantly. This is in fair agreement with the top of the pollution plume observed by LIDAR near $5^{\circ} \mathrm{N}$.

\section{Nested simulations using RAMS}

RAMS version 4.3 (http://www.atmet.com) is a primitive equation prognostic, non-hydrostatic model developed for the simulation and forecasting of weather systems (Cotton et 


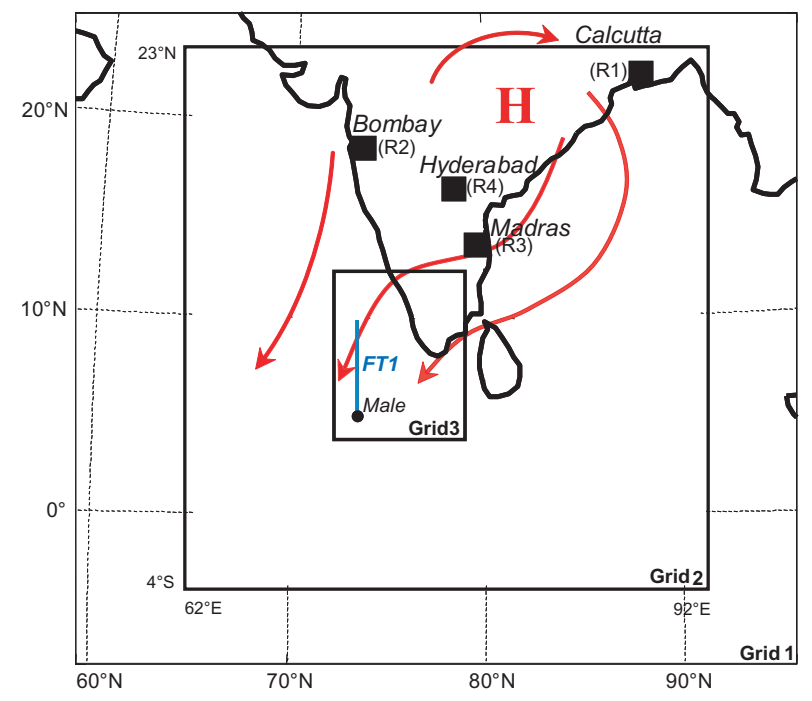

Fig. 4. Simulation domain with the position of the 3 nested grids and the 4 emission areas: Calcutta (R1), Bombay (R2), Madras (R3) and Hyderabad (R4). The squares materialize the emission areas prescribed in the model. The arrows represent the dominant circulation patterns during the period under scrutiny. All arrows are representative of the $850 \mathrm{hPa}$ level, except the arrow offshore from Bombay, which is representative of the $1000 \mathrm{hPa}$ level.

al, 2003). For this study, the turbulent closure scheme used is the scheme of Smagorinski (1963), modified following studies of Lilly (1962) and Hill (1974). The cloud convection is represented after an adjustment scheme from Kuo (1965) modified by Tremback (1990), for grids with higher horizontal resolutions (up to $10 \mathrm{~km}$ ), while a single-moment bulk scheme by Walko et al. (1995) and Feingold et al. (1998) is used to represent microphysics for finer grids. The model predicts soil temperature and moisture from the prognostic soil model, which takes into account the vegetation cover and the type of soil (Walko et al., 2000). Many studies on regional pollution have used RAMS (e.g. Lyons et al., 1995; Millan et al., 1997; Edy and Cautenet, 1998; Cautenet et al., 1999; Audiffren et al., 2004; Taghavi et al., 2004, 2005).

Three simulations were performed: the one-grid simulation (run A), the two-grid reference simulation involves two nested domains (run B) while the sensitivity simulation (run C) has three nested domains. The location of the two or three nested grids is shown in Fig. 4. Information between the domains is exchanged in two directions, using the scheme described in Clark et al. (1984) and Walko et al. (1995).

The largest domain, (grid 1) is bounded by meridians $58^{\circ} \mathrm{E}$ and $96^{\circ} \mathrm{E}$, and by parallels $25^{\circ} \mathrm{N}$ and $8^{\circ} \mathrm{S}$. This horizontal domain consists of $42 \times 38$ grid points, with the mesh size being $100 \mathrm{~km} \times 100 \mathrm{~km}$, and 35 sigma-z levels. The intermediate domain (hereafter referred to as grid 2) is centered on $77.5^{\circ} \mathrm{E}$ and $10^{\circ} \mathrm{N}$. It is composed of $152 \times 152$ points with a horizontal mesh size of $20 \mathrm{~km} \times 20 \mathrm{~km}$. The smallest domain (grid 3) has a horizontal resolution of $5 \mathrm{~km} \times 5 \mathrm{~km}$ and it is centered on $76^{\circ} \mathrm{E}$ and $8.5^{\circ} \mathrm{N}$. The time steps are 30 , 6 and $1.5 \mathrm{~s}$ for grid 1 , grid 2 and grid 3, respectively. The choice of the vertical resolution has been a critical point of the simulation. Indeed, preliminary simulations have shown that the vertical resolution should be high enough to correctly capture the ongoing dynamical processes along the western coastline, due to the presence of orography. Hence, we have chosen 35 vertical levels for the grid 1 and 62 levels for grids 2 and 3 between the ground and 22-km msl. Vertical levels are designed in $(\sigma, p)$ coordinates. With such a configuration we have 39 levels below 4000-m msl for grids 2 and 3, with a resolution ranging from $30 \mathrm{~m}$ for the first level to about $300-$ $\mathrm{m}$ at 4000-m msl (intervals follow a geometric progression with a ratio of 1.15 ).

The grid 1 simulation was driven by ECMWF (European Center for Medium-Range Weather Forecasts) re-analyses (available every $6 \mathrm{~h}$ ). The simulation begins at 00:00 UTC on 26 February and ends at 12:00 UTC on 9 March 1999.

The $1-\mathrm{km}$ resolution soil vegetation model (important to capture the breeze circulations over land) from USGS (United States Geophysical Survey) is used to described land use in the simulation. In the model, the topography is obtained by interpolating the available $1-\mathrm{km}$ resolution database to the mesh size of the nested domains. The sea surface temperature used in the model is based upon monthly climatologically data at $1^{\circ} \times 1^{\circ}$ resolution available from the ATMET database.

For this study, it is crucial that the dynamics in the simulation are as realistic as possible, in order for the model to reproduce the monsoon haze plume. The horizontal wind fields (wind barbs) simulated on the intermediate domain (grid 2) at 00:00 and 12:00 UTC on 7 March and at two levels $(850 \mathrm{hPa}$ and $500 \mathrm{hPa})$ are shown in Fig. 5. In this graph, the wind barbs are also shown which were extracted at these levels from the upper air soundings of the Indian network (see Fig. 1 for locations) when available. It can be seen that the agreement between the wind fields from RAMS simulations at 00:00 and 12:00 UTC are in very good agreement with the observations at $500 \mathrm{hPa}$ (Figs. 5a, b). The agreement is also good at the $850 \mathrm{hPa}$ (Figs. 5c, d), except maybe in some locations along the western coast, where the influence of the Ghats (a mountain ridge of moderate height running along the western coast of India) has generate local circulation that cannot necessarily be reproduced with the simulation. Nevertheless, the worse agreement is found over central India, in a region located near the center of the continental anticyclone, where winds are generally weak (e.g. in Aurangabad at 00:00 UTC or Nagpur at 12:00 UTC). The general agreement between observations and simulations in terms of dynamics was found to be good throughout the period of the simulation (not shown). This is crucial since the structure of tracer plume observed on 7 March 1999 is conditioned by the history of the airmasses for as long as 10 days (preliminary work demonstrated that beyond 10 days, the spin-up time allowed the final aerosol distribution did not change significantly). 

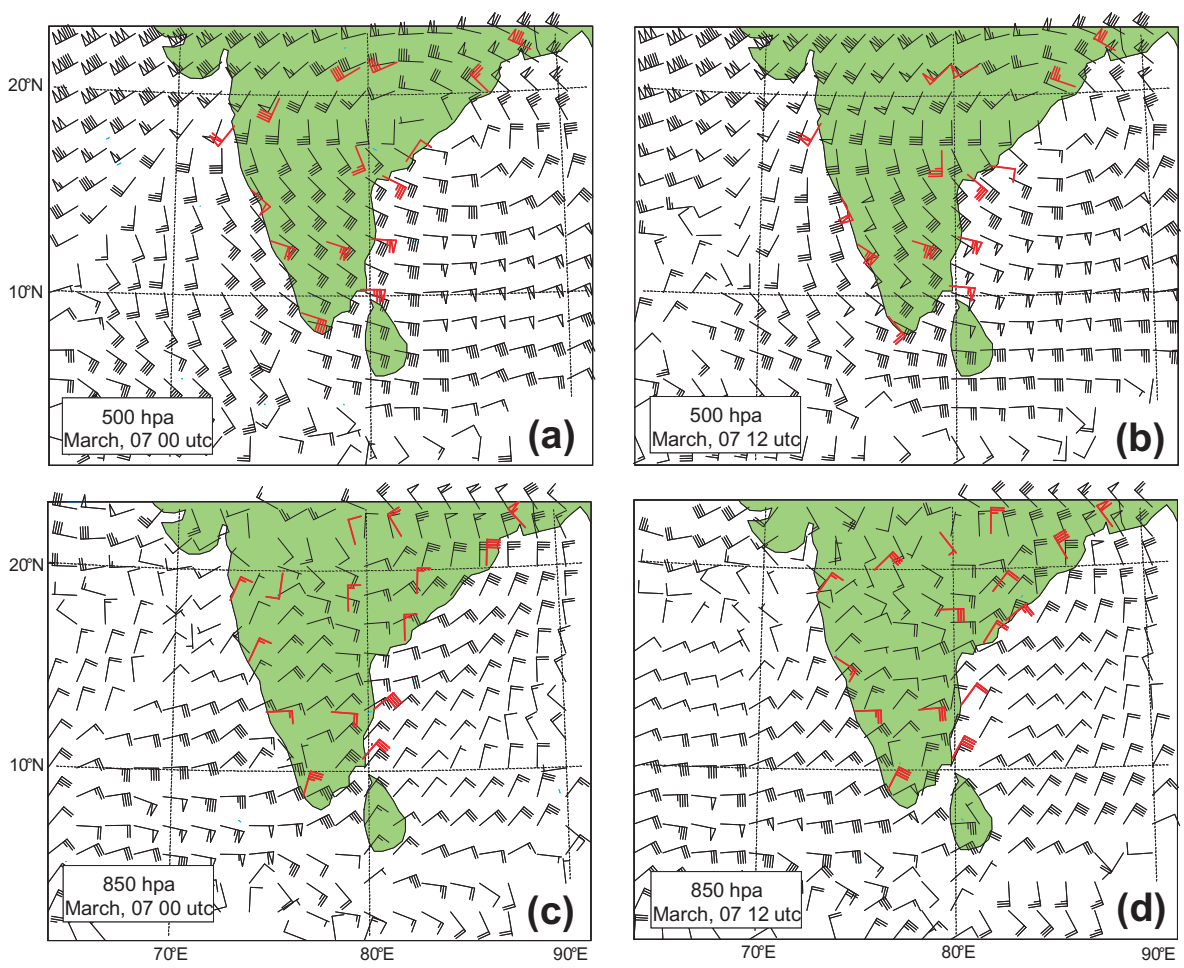

Fig. 5. Horizontal wind fields (black wind barbs) simulated on the intermediate domain (grid 2) at 00:00 UTC for the $500 \mathrm{hPa}$ (a) and $850 \mathrm{hPa}$ (c) levels on $7 \mathrm{March}$. Also shown are the wind fields at 12:00 UTC for the $500 \mathrm{hPa}$ (b) and $850 \mathrm{hPa}$ (d) levels on $7 \mathrm{March} 1999$. Also shown are the wind barbs extracted at the 500 and $850 \mathrm{hPa}$ levels from the upper air soundings of the Indian network (see Fig. 1 for locations), when available (red wind barbs). Long (short) ticks associated with the wind barbs correspond to $2 \mathrm{~m} \mathrm{~s}^{-1}\left(1 \mathrm{~m} \mathrm{~s}^{-1}\right)$, while triangles correspond to $10 \mathrm{~m} \mathrm{~s}^{-1}$

\section{Tracer simulations}

To analyse the 3-D structure of the Indo-Asian haze plume over the Arabian Sea, north of the Maldives, passive tracer sources, corresponding to 4 important emission areas, have been introduced. They have been selected based on the back-trajectory analyses performed by Pelon et al. (2002) for the 7 March 1999 case. The 4 emission regions are centered on Calcutta $\left(88.45^{\circ} \mathrm{E} ; 22.65^{\circ} \mathrm{N}\right)$, Bombay $\left(72.85^{\circ} \mathrm{E}\right.$; $\left.19.11^{\circ} \mathrm{N}\right)$, Hyderabad $\left(78.46^{\circ} \mathrm{E} ; 17.45^{\circ} \mathrm{N}\right)$, and Madras $\left(80.18^{\circ} \mathrm{E} ; 13^{\circ} \mathrm{N}\right)$, respectively and are hereafter referenced as R1, R2, R3, R4 (see Fig. 4). Emission rates are prescribed to be steady with time and to be consistent with the EDGAR 2.0 CO database (Olivier et al., 1996): emission rates in $\mathrm{R} 1$ and $\mathrm{R} 2$ are prescribed to be the same and equal to $10^{-6} \mathrm{ppb} \mathrm{m}^{-2} \mathrm{~s}^{-1}$, whereas emission rates in $\mathrm{R} 3$ and $\mathrm{R} 4$ are prescribed to be $75 \%$ of those in $\mathrm{R} 1$ and $\mathrm{R} 2$. Tracer concentrations are unitless (e.g. molecules of tracer/molecule of air). The objective is to assess whether the structure of the haze plume observed by LIDAR to the north and to the west of the Maldives Islands on 7 March 1999 can be reconstructed based on tracer simulations from the abovementioned sources. Finally, we must note that no deposition processes are taken into account for inert tracers, for exam- ple no rain-out and wash-out processes and no dry deposition. The zone (latitude up to $5^{\circ} \mathrm{N}$ ) and the period of interest (early March 1999) are dry enough to state that wet processes can be neglected. Moreover, aerosols observed over the ocean during INDOEX mainly exhibit a diameter smaller than $2 \mu \mathrm{m}$ (De Reus et al., 2001), characterized by weak sedimentation velocities (Slinn and Slinn, 1980) Finally, since we mainly study the transport of tracers over stable oceanic areas or in altitude, turbulent dry deposition at the surface is considered to be negligible, as well.

4.1 Origin of pollutants composing the haze plume sampled by LIDAR

Based on LIDAR observations on 7 March 1999, we have selected 2 altitude levels to look at the circulation patterns and the transport of aerosols from the continental sources: $100-\mathrm{m} \mathrm{msl}$ (in the MABL) and 2-km msl (at this level, haze was observed in both the shallow and deep plume regions).

Figure 6 shows the horizontal distribution of tracer concentration (at 03:00 UTC) associated with individual plumes emitted from R1, R2, R3, R4 after 9 days of simulation, at $100-\mathrm{m}$ msl, on grid 2 of the reference numerical experiment (run B) with superimposed horizontal wind vectors. The 

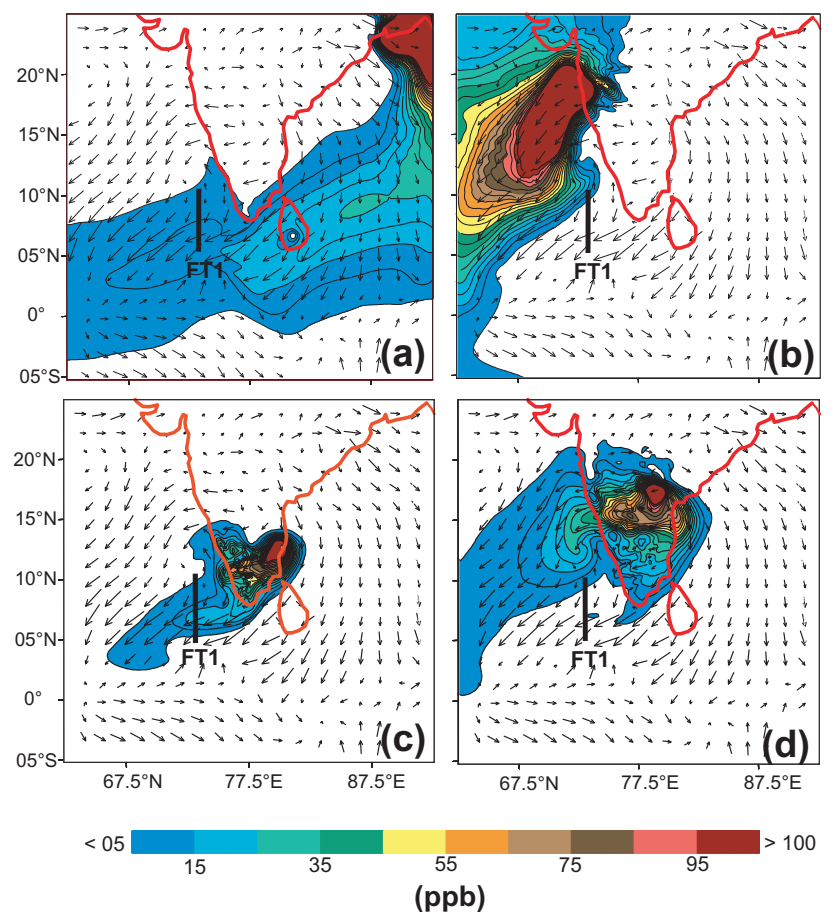

Fig. 6. Horizontal distribution of tracer concentrations (ppb) at 100m msl on 7 March 1999 at 03:00 UTC associated with sources located in (a) Calcutta, (b) Bombay, (c) Madras, and (d) Hyderabad for the reference simulation (run B) on grid 2 .

northern convergence zone is clearly seen along $0-5^{\circ} \mathrm{N}$, between $65^{\circ} \mathrm{E}$ and $90^{\circ} \mathrm{E}$, associated with the strong northeasterly and northerly outflows over the Arabian Sea and Gulf of Bengal, respectively. Tracers are simulated to be transported to the southwest of the Indian sub-continent as far as $2000 \mathrm{~km}$ from their emission sources after 9 days. The plume of pollutants can be visualized as the region where the tracer concentrations are larger than $5 \mathrm{ppb}$ (the value of $5 \mathrm{ppb}$ enabled the best description of the vertical structure of the plume in the simulation, as discussed later). The plumes from Calcutta and Bombay were simulated to travel over the ocean for the most part (Gulf of Bengal and Arabian Sea, respectively) (Figs. 6a and b), whereas plumes from Madras and Hyderabad (Figs. 6c and d) were simulated to travel over the Indian sub-continent prior to being advected over the Arabian Sea. It is worth noting that, even though most of the plume from Calcutta traveled over the Gulf of Bengal, the northern portion of it (i.e. the portion arriving over the M-20 track) had traveled partly over the continent. As discussed later, the vertical distribution of tracer concentration in the plumes originating from Madras and Hyderabad (and to a lesser extent the northern portion of the Calcutta plume) were impacted by the diurnal cycle of convection over land. At this height, it appears from the simulations that the aerosols sampled by LIDAR along FT1 in the MABL were associated with the plume from Madras and Calcutta.

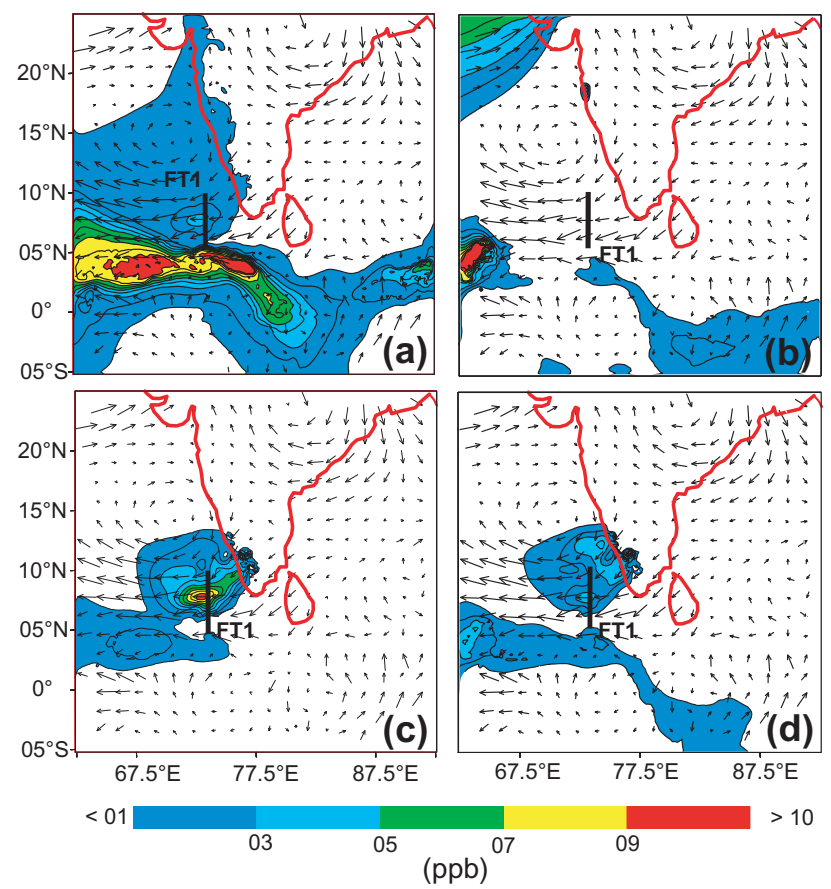

Fig. 7. Horizontal distribution of tracer concentrations (ppb) at 2000-m msl on 7 March 1999 at 03:00 UTC associated with sources located in (a) Calcutta, (b) Bombay, (c) Madras, and (d) Hyderabad for the reference simulation (run B) on grid 2.

Figure 7 shows the horizontal distribution of tracer concentration (at 03:00 UTC) associated with individual plumes emitted from R1, R2, R3, R4, after 9 days of simulation, at $2000-\mathrm{m} \mathrm{msl}$. Here also the northern convergence zone is clearly seen along $0-5^{\circ} \mathrm{N}$, between $65^{\circ} \mathrm{E}$ and $77.5^{\circ} \mathrm{E}$, over the Arabian Sea. The subtropical high is seen over northeastern Indian, while another anticyclonic feature is seen offshore from the Indian west coast over the Arabian Sea (the same features are also simulated at 3500-m msl, not shown). The high concentrations of tracers simulated along the Indian western coastline in Figs. 7c and d are connected to the explosive combination of breeze and orographic lifting (cf. Sect. 2.2). As discussed later, on the basis of the simulations, this effect is maximum at 12:00 UTC on the continent. It appears from the simulations that the aerosols sampled by LIDAR along FT1, above the MABL, were mainly associated with plumes from Madras and Hyderabad, and to a lesser extend with the plume from Calcutta.

More south, between $5^{\circ} \mathrm{N}$ and $5^{\circ} \mathrm{S}$, high tracer concentrations are also simulated around 2000-m msl. Such a feature is observed for all sources (Fig. 7) but it is more important for the tracer issued from Calcutta (Fig. 7a). This area correspond to the intertropical convergence zone, where important convective clouds are simulated, as seen on Fig. 8, displaying simulated liquid water mixing ratio integrated from the ground to the top of the grid. 


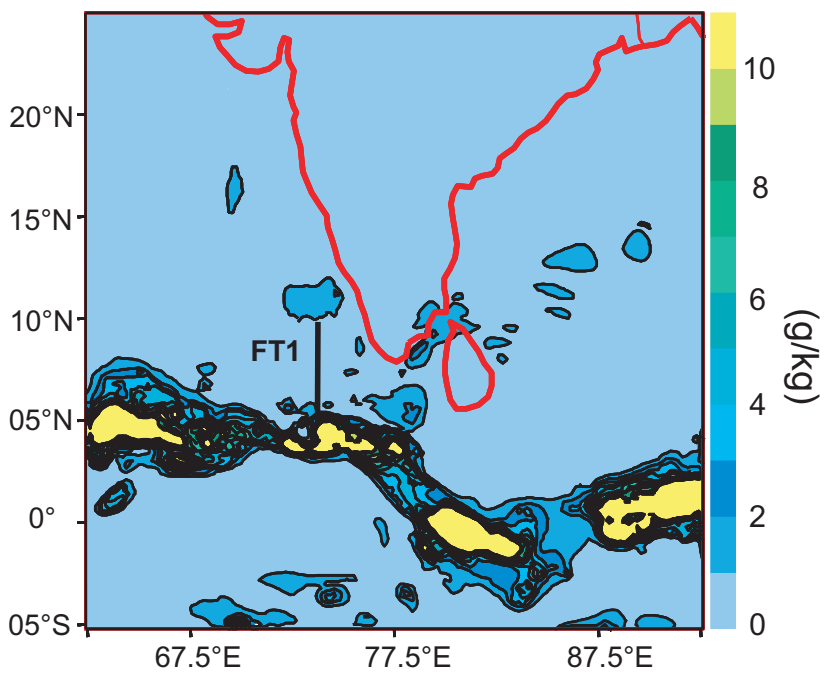

Fig. 8. Horizontal distribution of liquid water mixing ratio $(\mathrm{g} / \mathrm{kg})$ vertically integrated from the ground to the top on 7 March 1999 at 03:00 for the reference simulation (run B) ion grid 2 .

\subsection{Vertical structure of the simulated plume}

The vertical distribution of tracer concentration (a proxy of the structure of the plume) along the M-20 flight track (FT1) obtained from the 2-grid reference simulation (run B) on grid 2 is shown in Fig. 9a. This tracer concentration field is obtained by summing the individual tracer fields from all 4 emission sources. In order to ensure a meaningful comparison of the tracer concentration cross section with the LIDAR-derived ABC cross section, one must be aware that careful analysis of the relative humidity (RH) field is essential (Fig. 9b). For hydrophilic aerosols (such as MABL aerosols), it is generally considered that above RH values of $75 \%$, aerosol size swells by absorption of water vapor, which leads to a drastic modification of the aerosol optical properties. For such aerosols, LIDAR ABC is generally observed to increase with RH for a well-mixed concentration profile. For hydrophobic aerosols (such as the pollution aerosols transported from the Indian sub-continent (Cantrell et al., 2000, 2001; Twohy et al., 2001; Chazette, 2003), RH has little impact on the aerosol scattering properties. Hence, maximum values in the LIDAR ABC field can be interpreted as maximum values in aerosol concentration (which is not a sound hypothesis in the MABL).

In the simulation, the MABL is identified as the layer characterized by high RH (90\% or more) and large tracer concentration (the highest tracer concentrations are found in the MABL). The depth of the MABL decreases with increasing latitude, from $1500 \mathrm{~m}$ to the south, to $600 \mathrm{~m}$ to the north (Fig. 9b). Dropsonde measurements presented in Fig. 3a evidence a deeper MABL in the southern part of the track over the Arabian sea. This is believed to be caused by higher SSTs to the south. A $2^{\circ} \mathrm{C}$ decrease is seen in the weekly Reynolds
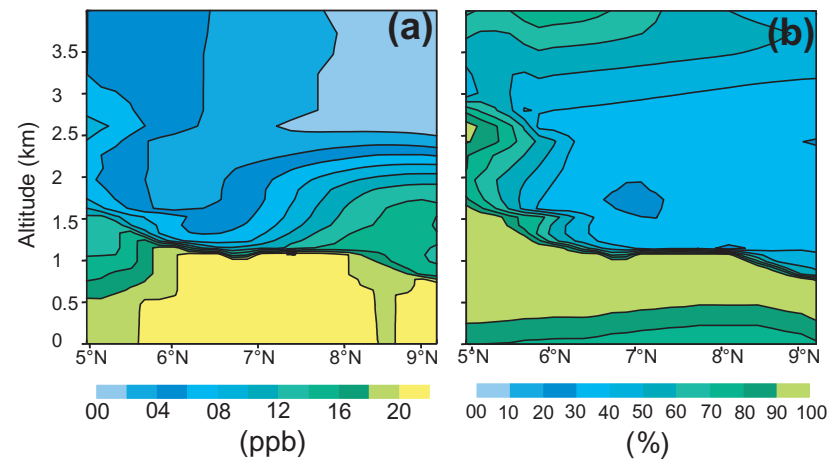

Fig. 9. Vertical distribution of the tracer concentration (ppb) (a) and relative humidity (b) along FT1 obtained with the reference simulation (run B) ion grid 2 at 03:00 UTC on 7 March 1999. The tracer field in (a) is the sum of the tracer fields from the four emission sources.

SST field along the east-west C-130 track (dropsondes 5 to 12). The decrease in temperature between 8 and $12^{\circ} \mathrm{N}$ is not as important, on the order of $0.5^{\circ} \mathrm{C}$, but is consistent with the observed decrease in the MABL top height. Aloft, in the haze plume, the RH is less than $40 \%$ around $2-\mathrm{km}$ msl. In the southern part of the transect (FT1), RH increases near the top of the plume where higher clouds are simulated. This is in good agreement with the RH measurements made over Male with the M-20, which showed that RH varied between 60 and $80 \%$ near the surface, reaching values of $95 \%$ or more at the MABL top. Aircraft measurements in the plume aloft revealed that $\mathrm{RH}$ was on the order of $40 \%$, except near the top of this layer where RH increased sharply to $80 \%$, as generally observed in the winter monsoon flows (Mohanty et al., 2001; Manghnani et al., 2000).

In the following, we define the altitude of the top of the plume as the altitude of iso-contour $5 \mathrm{ppb}$ ( $5 \mathrm{ppb}$ has been chosen as the best fit between simulated plume and Lidar observations). North of $6^{\circ} \mathrm{N}$, the general structure of the plume is reasonably simulated, even though the altitude of the top of the plume is approximately $400 \mathrm{~m}$ too low for the northern part of the transect (where the observed plume is thicker). Furthermore, the maximum of LIDAR-derived $\mathrm{ABC}$ (related to a maximum of aerosol concentration and/or $\mathrm{RH}$ ), observed between $8^{\circ} \mathrm{N}$ and $9^{\circ} \mathrm{N}$ around $2.25-\mathrm{km} \mathrm{msl}$, is not simulated. This could be due to the coarse representation (i.e. a mesh size of $20 \mathrm{~km}$ ) of the coastal dynamics, resulting in a weaker vertical development of the continental boundary layer (CBL), as discussed in the next section. However, the top of the land plume defined by the RH increase ( $40 \%$ to $80 \%$ ) is consistent with LIDAR observations. As $\mathrm{RH}$ has a non negligible effect on LIDAR ABC, one has to be careful when comparing simulation-derived tracer fields with LIDAR-derived ABC fields.

South of $6^{\circ} \mathrm{N}$, the tracer plume is deeper than observed by LIDAR. However, the interpretation of the concentrations 

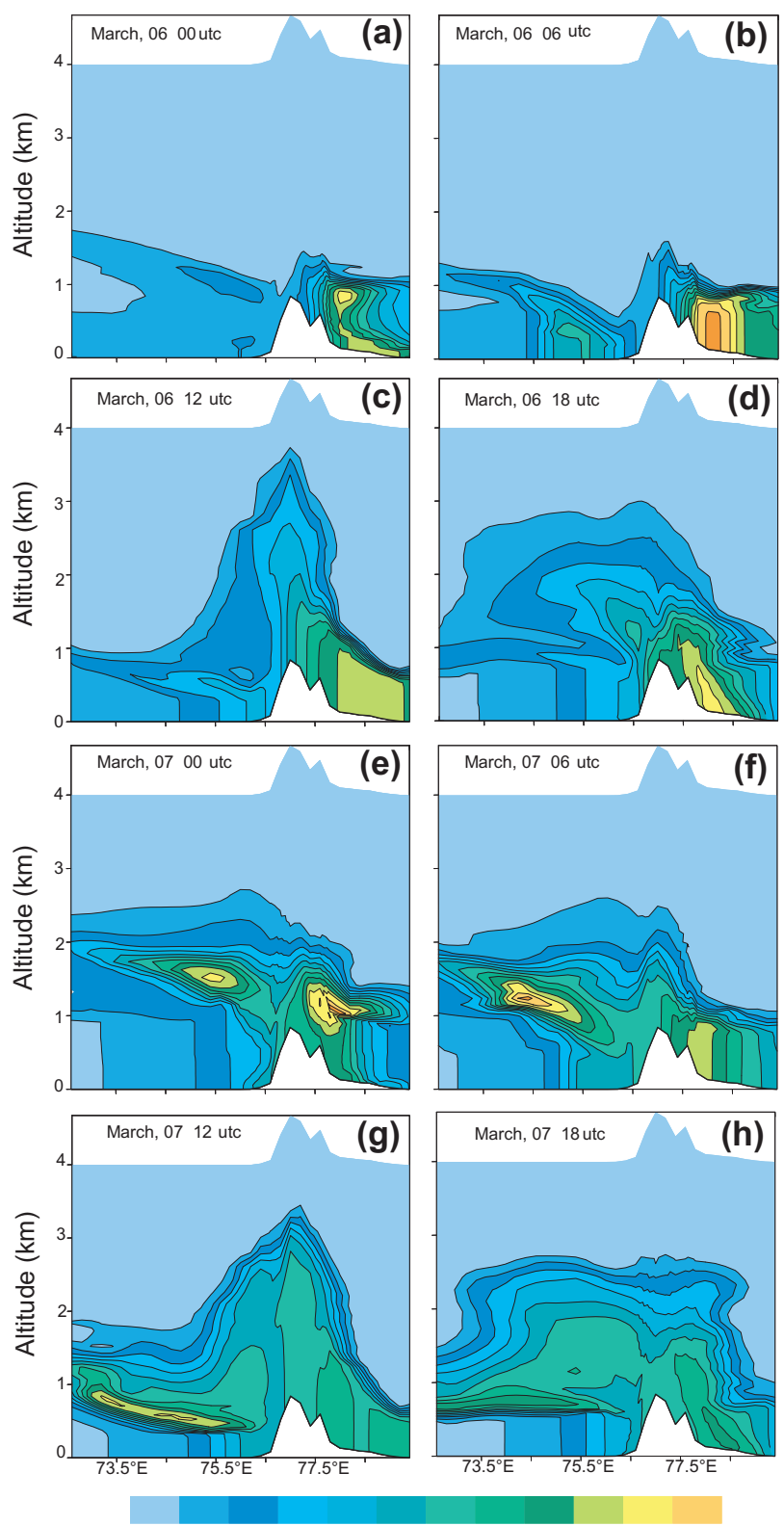

00

10

20

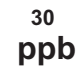

Fig. 10. Vertical distribution of the tracer concentration $(\mathrm{ppb})$ at $10^{\circ} \mathrm{N}$ latitude and between $73^{\circ} \mathrm{E}$ and $78.5^{\circ} \mathrm{E}$, obtained with the 2grid reference simulation (run B) at (a) 00:00, (b) 06:00, (c) 12:00, (d) 18:00 UTC on 6 March and at (e) 00:00, (b) 06:00, (c) 12:00, (d) 18:00 UTC on 7 March 1999.

simulated in the southern part of the transect is difficult. As shown in Fig. 7, the southern part of FT1 is embedded in the northern convergence zone. Hence, in the simulation, strong convective towers transport the tracers in altitude. The presence of the northern convergence zone in this region also explains the deeper MABL and the poor agreement between the observed structure and the simulated one. LIDAR observations (Fig. 2) do not suggest the presence of the northern convergence zone as far north as $5-6^{\circ} \mathrm{N}$. Hence, it is not believed that in this region the comparison of simulated and observed $\mathrm{ABC}$ will be in agreement.

\subsection{Tracer plume diurnal evolution and propagation over the ocean}

During the daytime, the combination of sea breeze circulation and orographic lifting induced by the presence of the Western Ghats has a profound influence on the structure of the land plume (Mohanty et al., 2000; Roswintiarti et al., 2001; Léon et al., 2001; Ethé et al., 2002). Krishnamurti et al. (1998) have suggested that the depth of the elevated pollution plume transported over the ocean was controlled by the diurnal variability of the CBL and the height of the trade wind inversion layer. This was confirmed by LIDAR measurements made in Goa during the IFP (Chazette, 2003), which evidenced the diurnal cycle of the AOD and the extinction coefficient profiles. Along the Indian west coast, the altitude of the top of the pollution plume varied between 3- and 4-km msl, with the deeper plume depths being observed at 12:00 UTC (Chazette, 2003). Continental aerosols are generally observed to be mixed on the vertical throughout the depth of this land plume (Léon et al., 2001; Raman et al., 2002). Temperature profiles obtained from synoptic balloon soundings in Goa during the period running from 6 to 9 March 1999 show the presence of an elevated temperature inversion at this level, fluctuating between 3- and 4-km msl (not shown). This is also seen on dropsonde measurements performed west of the continent by the Met Office C-130 (Fig. 3a). A maximum height of the inversion is observed on profile 5, which is the closest to the shoreline (see Fig. 2). Other profiles show a lower inversion altitude, which can be attributed to large-scale subsidence. Such an explosive combination of breeze and orographic lifting cannot occur at night, so that the CBL is much shallower.

During the period from 12:00 UTC on 5 March to 12:00 UTC on 9 March 1999, the impact of coastal dynamics on the aerosol plume spatio-temporal structure is well marked. This is illustrated in Fig. 10, where we show a vertical cross section of the tracer concentration $(\mathrm{ppb})$ at $10^{\circ} \mathrm{N}$ latitude and between $73^{\circ} \mathrm{E}$ and $78.5^{\circ} \mathrm{E}$, obtained with the 2grid reference simulation (run B) every $6 \mathrm{~h}$ from 00:00 UTC on 6 March 1999 to 18:00 UTC on 7 March 1999. A 24$\mathrm{h}$ periodic cycle takes place, of which the main phases can be describe as: (i) a strong vertical development of the CBL during the day (as deep as $3-4 \mathrm{~km}$ ), in which aerosols are well mixed vertically, with a maximum vertical development of the layer between 12:00 and 15:00 UTC; (ii) a horizontal advection of the haze plume corresponding to the upper part of the CBL over the ocean by the winter monsoon flow (15:00-00:00 UTC), and (iii) a subsidence of the plume over the ocean (00:00-12:00 UTC).

Unfortunately, very little observations were available during INDOEX to verify the validity of this proposed scheme 


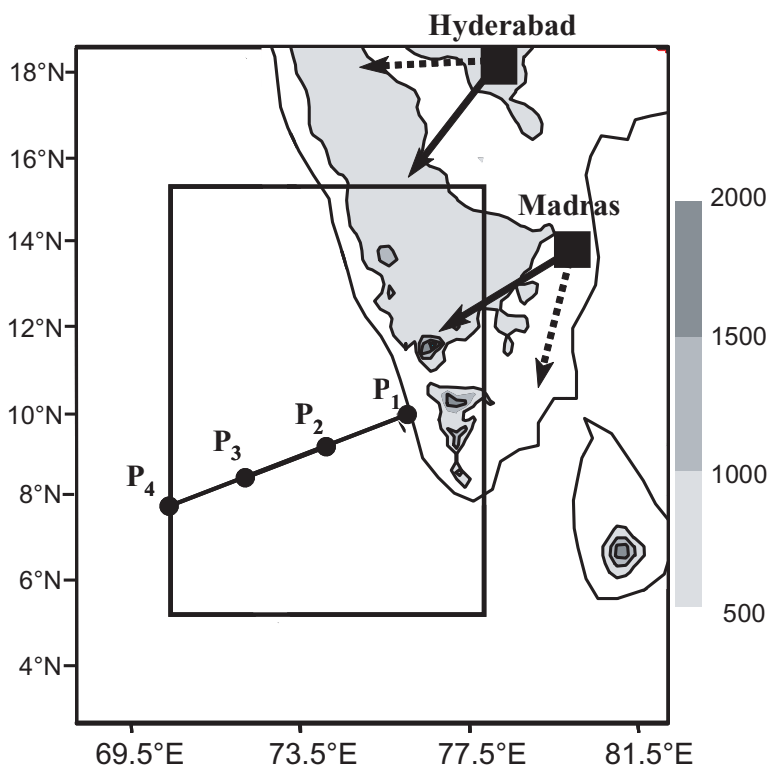

Fig. 11. Map of south India (with terrain elevation) and position of the 4 locations used to inspect the spatial and temporal structure of pollutants plume over the ocean: P1 (76.5_E; 10_N), P2 (74.3_E; 9.3_N), P3 (72.7_E; 8.6_N), P4 (69.9_E; 7.6_N). Dotted (solid) arrows represent the main wind direction before (after) 6 March 1999.

over the Arabian Sea. Although the influence of this diurnal variability on the optical properties of the continental plume has been highlighted on Meteosat images in the form of frontal discontinuities in the brightness surface temperature fields oriented parallel to and propagating away from the coastline (Désalmand et al., 2003), little relevant information on the vertical structure of the pollution plume and its evolution over the sea was available. A three-day Sun-photometer AOD sequence acquired from the R/V SK, close to the west Indian coast (see Fig. 1), proved to be more reliable for observing of the diurnal cycle of the optical properties of the pollution plume (the R/V SK was cruising slowly along the coast). We also have used the LIDAR measurements made in Goa (Chazette, 2003) for validation purposes in the coastal region of India.

For comparison with available LIDAR and Sunphotometer data sets, we display the temporal variations of simulated concentrations at 2000-mmsl (upper part of the plume) at four locations (P1 through P4) along a transect approximately perpendicular to the west Indian coast and roughly parallel to the mean wind direction at 2000-m msl (see Fig. 11) for this period. The four locations are equidistant.

The tracer concentration at 2000-m msl at the coastal site $\left(\mathrm{P} 1,76.5^{\circ} \mathrm{E} / 10^{\circ} \mathrm{N}\right)$ exhibits a well established diurnal cycle with maximum values at about 12:00-15:00 UTC and minimum values at 06:00 UTC, consistent with the first two phases described above (Fig. 12). Furthermore, maxima

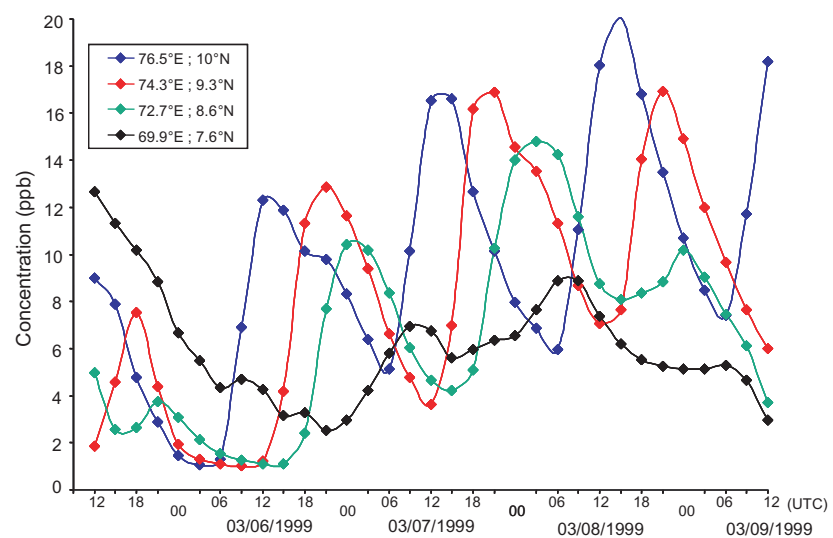

Fig. 12. Diurnal evolution of the top of the tracer plume (ppb, at $2000 \mathrm{~m} \mathrm{msl}$ ) between 5 March (12:00 UTC) and 9 March (12:00 UTC), along the mean winds line for (P1, blue), (P2, red), (P3, green) and ( $\mathrm{P} 4$, black) from the high resolution simulation (run C) on grid 2.

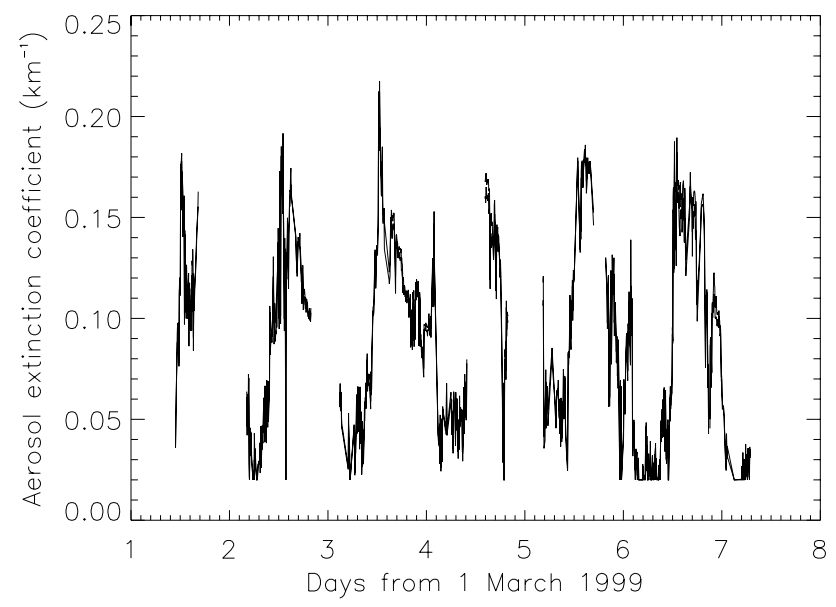

Fig. 13. LIDAR extinction coefficient (at $532 \mathrm{~nm}$ ) measured in Goa at 2000-m msl between 1 and 8 March 1999.

(minima) of the LIDAR-derived aerosol extinction coefficient observed at this height in Goa occur at the same time as in the simulation, i.e. around 12:00 (06:00) UTC (Fig. 13). For a given day, the concentration build-up phase (06:0015:00 UTC) is always shorter than the concentration decay phase (15:00-06:00 UTC). This is also in remarkable agreement with the extinction coefficient at 2000-m msl (Fig. 13) for a period running from 1 to 8 March 1999. The extinction coefficient is observed to increase more rapidly than it decreases in the course of the diurnal cycle. Hence, the diurnal evolution of the observed extinction coefficient and the simulated tracer concentration are strikingly similar. Recall that the pollution aerosols produced by India were shown to be hydrophobic, and hence both quantities can be compared directly. In Fig. 12, it is also worth noting the increase in concentration in P1 (P2) from 6 to 8 March, on the order 


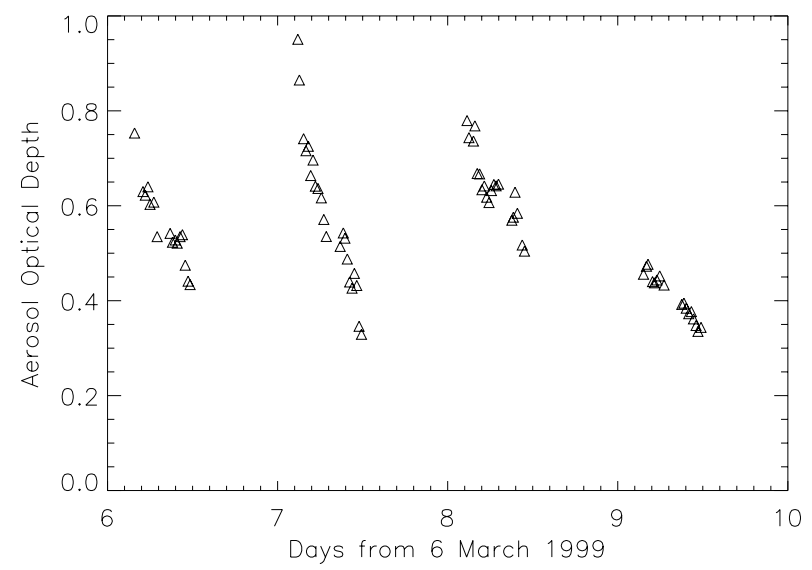

Fig. 14. Sun-photometer aerosol optical depth (at $497 \mathrm{~nm}$ ) measured on board the R/V SK between 6 and 10 March 1999. The position at which the measurements were made is shown in Fig. 1.

of $40 \%(25 \%)$. This is not caused by enhanced emissions over the continent, since in the simulation the emissions are constant. This significant increase is also believed not to be due to accumulation (caused by the lack of dry deposition in the simulation), as dry deposition at this level (2000-m msl, above the MABL) is likely to be insignificant. Furthermore, the strength of the flow at this level $\left(10 \mathrm{~m} \mathrm{~s}^{-1}\right.$ or more) is likely to act against accumulation, leading to rapid dispersion of the pollutants.

To obtain further insight into this concentration increase, we have computed a spatially averaged daily mass budget, for a region windward of the southern west coast of India between $15^{\circ} \mathrm{N}$ and $5^{\circ} \mathrm{N}$ and $70^{\circ} \mathrm{E}$ and $78^{\circ} \mathrm{E}$ (Fig. 11) and between the surface and $5-\mathrm{kmmsl}$, for the time period running from 5 March 1999 (12:00 UTC) to 9 March 1999 (12:00 UTC). The total mass of tracers (sum of the 4 tracers) was found to increase by a factor of 2.5 between 5 and 9 March. While considering separate sources, the increase reached 2.5 and 4 for tracers from Madras and Hyderabad, respectively. This increase is due to enhanced horizontal advection from the southern Indian continent towards the Arabian Sea. In Madras, the dominant winds $(850 \mathrm{hPa})$ are shifting from north-northeasterly to northeasterly between 5 and 6 March (Fig. 11). In Hyderabad winds are shifting from easterly to northeasterly during the same period. The increase in tracer concentration simulated in P1, P2 and P3 is associated with these wind shifts, as a result of enhanced tracer transport in the region of interest. Likewise, the contribution from Calcutta is decreasing (by a factor of 3 ) but represents a weaker part of the total mass (17\%) with respect to the contribution by Hyderabad and Madras (63\%). The contribution from Bombay is increasing by a factor of nearly 10 (i.e. Bombay contributed nearly nothing on 5 March), as the wind direction at $850 \mathrm{hPa}$ shifts from westerly to northnorthwesterly (i.e. parallel to the coastline) between 5 and 6 March. Nevertheless, the contribution from Bombay re- mains mainly below $1 \mathrm{~km}$ a.s.l. These changes in pathways are likely related to the eastward shift of the subtropical high from central India to the Bay of Bengal after 6 March 1999, as the Indian sub-continent began to heat up.

For the first cycle (6-7 March), the tracer concentration at the P2 $\left(74.3^{\circ} \mathrm{E} / 9.3^{\circ} \mathrm{N}\right)$ and $\mathrm{P} 3\left(72.7^{\circ} \mathrm{E} / 8.6^{\circ} \mathrm{N}\right)$ exhibits the same diurnal cycle as $\mathrm{P} 1$, with a shift of $6 \mathrm{~h}$ and $12 \mathrm{~h}$, respectively. Interestingly, over the ocean, the tracer concentration evolution is reminiscent of a propagating front. The propagation speed between P1 and P3 is relatively constant and on the order of $13 \mathrm{~m} \mathrm{~s}^{-1}$, consistent with the propagation speed of cloud bands traveling westward over the Arabian Sea ahead of the Indian pollution plume assessed using Meteosat-5 imagery (Désalmand et al., 2003). In P4 $\left(69.9^{\circ} \mathrm{E} / 7.6^{\circ} \mathrm{N}\right)$, a slight increase in tracer concentration is seen at 06:00 UTC on 7 March, which is not necessarily associated with the propagating tracer plume. During the second cycle (7-8 March), the tracer concentrations in P1, P2 and $\mathrm{P} 3$ exhibit the same general trend as during the first cycle, with the propagation speed of the tracer plume also being on the order of $13 \mathrm{~m} \mathrm{~s}^{-1}$ between P1 and P3. The third cycle (8-9 March) resembles that of the other two, except that the signature of the arrival of the tracer plume in P3 is weaker. During the period under scrutiny, there is also a significant correlation between what is simulated in $\mathrm{P} 4$ and in the other locations, suggesting long range transport of tracers in the simulation.

In Fig. 14, we show the AOD derived from a photometer installed on the R/V SK for a period ranging from 5 to 8 March 1999, close to the coastline (see Fig. 1). During this period, the R/V SK equivalent distance to the coast is comprised between $\mathrm{P} 2$ and $\mathrm{P} 3$. The strong AOD diurnal cycle is evident, suggesting large diurnal fluctuations of the aerosol content in the monsoon layer over the Arabian Sea, in agreement with tracer concentration variations in $\mathrm{P} 2$ and $\mathrm{P} 3$.

Further insight into the vertical transport of pollutants in the CBL was also obtained by analyzing the mass budgets performed windward of the southwestern Indian coast (inner box in Fig. 11) in run B. Mean tracer concentrations, normalized by the total mass concentration (i.e. sum of the 4 tracers mass concentrations), associated with the four cities under scrutiny are given in Table 1 . Between the surface and $5-\mathrm{km} \mathrm{msl}$, the largest contributions are simulated from the Madras (33\%) and Hyderabad (28\%) areas, with a non negligible contribution from Bombay (21\% mainly in the western part of the domain) and Calcutta (18\% mostly in the southern part of the domain). The fraction of the total tracer concentration above $1-\mathrm{km} \mathrm{msl}$ is approximately $30 \%$ of the total amount of tracers between the surface and 5-km msl. The contribution from Bombay ( $1 \%$ of the total) is insignificant above $1-\mathrm{km}$ msl, since the plume issued from R2 is mostly advected in the MABL. The contributions from Madras (13\% of the total mass) are nearly twice that from Calcutta (7\% of the total mass) and 1.5 times that from Hyderabad (9\% of the total mass). 
Table 1. Mean mass concentrations averaged on the $(\Sigma)$ horizontal area (cf. Fig. 11) between 0 and 5 km a.s.l. and between the 5 March 1999 , 12:00 UTC and 9 March 1999, 12:00 UTC for the 4 emission regions (R1, R2, R3, R4). All values are normalized by the total mean mass concentration. Results are presented in terms of total normalized mass for run B (i.e. horizontal resolution of $20 \mathrm{~km} \times 20 \mathrm{~km}$ ), normalized mass up to 1-km a.s.l. for run B and normalized mass up to 1-km a.s.l. for run C (i.e. horizontal resolution of $5 \mathrm{~km} \times 5 \mathrm{~km}$ ).

\begin{tabular}{lccc}
\hline & $\begin{array}{c}\text { Norm. mass (total) } \\
\text { Run B }(20 \mathrm{~km} \times 20 \mathrm{~km})\end{array}$ & $\begin{array}{c}\text { Norm. mass }(>1 \mathrm{~km} \text { a.s.1. }) \\
\text { run B }(20 \mathrm{~km} \times 20 \mathrm{~km})\end{array}$ & $\begin{array}{c}\text { Norm. mass }(>1 \mathrm{~km} \text { a.s.1. }) \\
\text { run C }(5 \mathrm{~km} \times 5 \mathrm{~km})\end{array}$ \\
\hline Calcutta (R1) & 0.18 & 0.07 & 0.07 \\
Bombay (R2) & 0.21 & 0.01 & 0.01 \\
Madras (R3) & 0.33 & 0.13 & 0.20 \\
Hyderabad (R4) & 0.28 & 0.09 & 0.10 \\
Total & 1 & 0.3 & 0.38 \\
\hline
\end{tabular}

\subsection{Sensitivity experiment}

Wang et al. (2004) have shown the importance of high horizontal resolution to correctly handle vertical transport of pollutants at larger scales. Similarly, Lyons et al. (1995) evidenced that in complex coastal areas, accurate modeling of dynamic, and particularly vertical fluxes, strongly depends on the horizontal resolution used in models. Furthermore, numerical diffusion can have important effects on the vertical transport of tracers. However, the effect of numerical diffusion is beyond the scope of this paper and has not been investigated. Nevertheless, it worth noting that increasing horizontal resolution reduces numerical diffusion, thereby allowing for more realistic vertical distribution of tracers.

To investigate the impact of grid resolution on the vertical structure of the simulated plume, we compare vertical winds and the structure of the tracer plume on a transect running along latitude $10^{\circ} \mathrm{N}$ on the Indian sub-continent, between $73^{\circ} \mathrm{E}$ and $79^{\circ} \mathrm{E}$, resulting: (i) from run $\mathrm{A}$ on grid 1 (referred to as S1, Figs. 15a and b), (ii) from run B on grid 2 (referred to as S2, Figs. $15 \mathrm{c}$ and d), and (iii) from run $\mathrm{C}$ on grid 2 (referred to as S3, Figs. 15e and f). The simulation results shown in Fig. 15 are obtained for the sum of the 4 emission sources and correspond to 6 March 1999 at 12:00 UTC, where the vertical development of continental plume is maximum.

The explosive combination of sea breeze, orographic lifting and CBL development over the Indian west coast is more efficient for S3 than for S1. This is likely related to the fact that over land, vertical motion resulting from the combination of sea breeze, orographic lifting and turbulent mixing is enhanced in S3 due to higher resolution, less smooth dynamics and orography, and more realistic wind fields. Indeed, where vertical velocities never exceed values of $5 \mathrm{~cm} \mathrm{~s}^{-1}$ in S1 (characteristic of GCM resolutions; Fig. 15a), they can reach values of $15 \mathrm{~cm} \mathrm{~s}^{-1}$ in S2 (configuration used in Sects. 4.1 and 4.2; Fig. 15b) and values of $30 \mathrm{~cm} \mathrm{~s}^{-1}$ in S3 along the western ridges of the Ghats. As a consequence, tracers are injected higher in the troposphere over
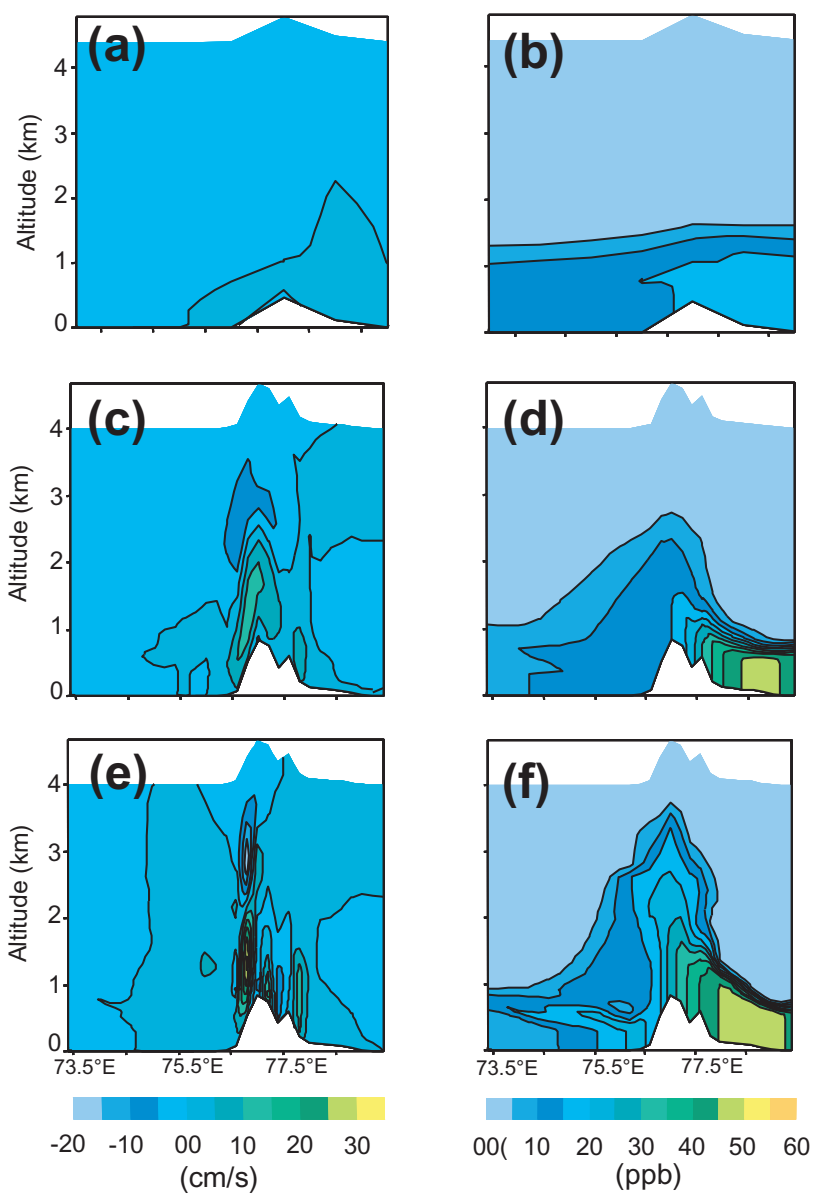

Fig. 15. Vertical distribution of the tracer concentration $(\mathrm{ppb})$ and vertical velocity $\left(\mathrm{cm} \mathrm{s}^{-1}\right)$ at $10^{\circ} \mathrm{N}$ latitude and between $73^{\circ} \mathrm{E}$ and $78.5^{\circ} \mathrm{E}$, respectively, obtained with the 1-grid simulation (run A) referred to as S1 (a) and (b), with the 2-grid reference simulation (run B), referred to as S2 (c) and (d) and with the high resolution simulation (run C), referred to as S3 (e) and (f) at 12:00 UTC on 7 March 1999. 


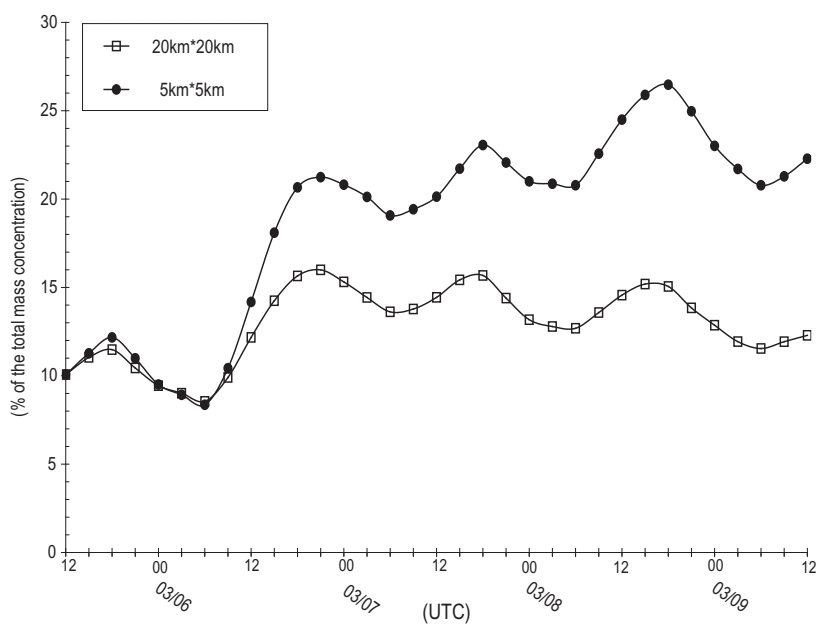

Fig. 16. Diurnal evolution of the mean mass concentrations (normalized by the total mass concentration) of the Madras tracer above $1 \mathrm{~km}$ a.s.l. as a function of time for run $\mathrm{B}$ (open squares) and run $\mathrm{C}$ (filled circles).

the Western Ghats, with the top of the tracer plume reaching 3.5-km msl (Fig. 15f). Over the ocean, the depth of the plume decreases (slightly) with increasing resolution.

Tracer mass concentration budgets made in the case of run $\mathrm{C}$ (i.e 5-km horizontal resolution) indicate (Table 1) an increase of $8 \%$ in the total mass transported above $1-\mathrm{km} \mathrm{msl}$ with respect to run B (20-km horizontal resolution). This increase is mainly due to the Madras tracer, which undergoes the longest transport over the continent and therefore is the most sensitive to the vertical flux increase associated with the increased horizontal resolution. This is illustrated in Fig. 16, showing mean mass concentrations (normalized by the total mass concentration) of the Madras tracer above 1-km a.s.l. as a function of time for a "run B" case and a "run C" case. In both cases the diurnal cycle associated with the daily development of the continental layer is present but the vertical transport is clearly more efficient in the case of the simulation with finer horizontal resolution.

In Fig. 17, we show the vertical distribution of tracer concentration along FT1 obtained from the high resolution simulation in grid 3 (run C) on 7 March 1999 at 03:00 UTC. The tracer concentration field in Fig. 16 is obtained by summing the individual tracer fields from all 4 emission sources. Comparing the distribution from S2 (Fig. 9a) to the observation (Fig. 2), the structure of the plume is better retrieved, with the exception of the southern part due to the presence of the northern convergence zone in the simulation, as discussed earlier. On the other hand, the tracer concentration maximum simulated at 2000-m msl between $8^{\circ} \mathrm{N}$ and $9^{\circ} \mathrm{N}$ and the associated minimum below is reminiscent of the LIDAR ABC structure observed in this region, which is a consequence of the better representation of coastal dynamics in run C.

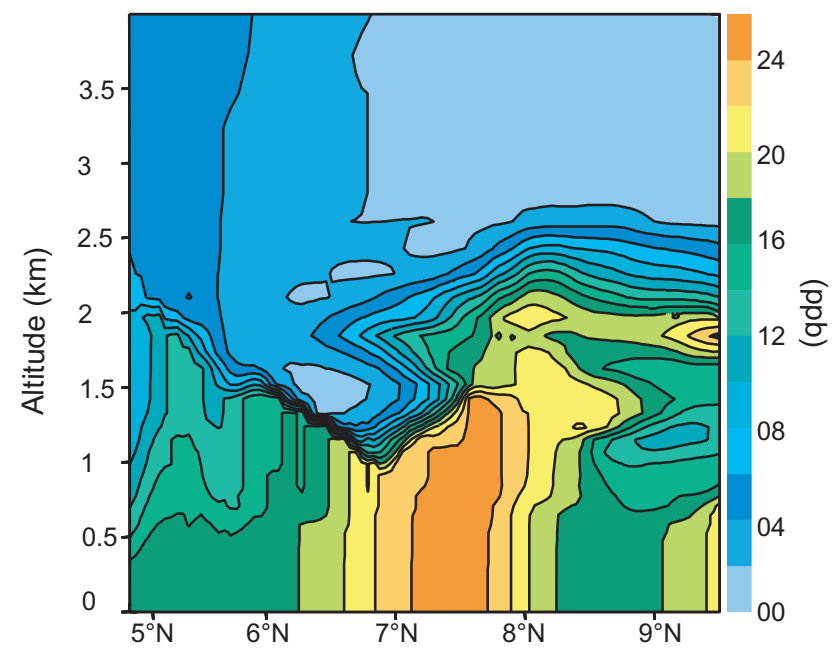

Fig. 17. Vertical distribution of the tracer concentration (ppb, all sources) along FT1 obtained with the sensitivity high resolution simulation ion grid 3 (run C) at 03:00 UTC on 7 March 1999. The contours are obtained by summing the tracer fields from the four emission sources.

\section{Summary and conclusion}

Three-dimensional, nested tracer simulations of a pollution plume transported from the Indian sub-continent over the Indian Ocean, in the framework of INDOEX, between 5 and 9 March 1999, were performed with RAMS. These simulations provide insight into the transport patterns of the pollutants, as well as investigate the dynamical mechanisms controlling the vertical structure of the plume and its evolution in the vicinity of the Maldives Islands. Airborne and ground-based LIDAR observations of the structure of the haze plume made on 7 March 1999 were used to assess the quality of the simulations, as well as the impact of grid resolution on the vertical structure of the simulated plume. Twelve dropsondes released by the Met Office C-130, ground-based backscatter LIDAR measurements made at Goa, respectively, as well as ship-borne Sun-photometer measurements made on the R/V SK, were also used in this study.

The focus of this paper is to assess whether the transport patterns leading to the simulated 3-D structure of the plume made with the RAMS over the Indian Ocean in the vicinity of the Maldives Islands are consistent with observations made by LIDAR on board the M20. At this point we have only considered passive tracers as a proxy for anthropogenic aerosols. We also have not considered the whole Indian sub-continent as a source region, but rather we have selected 4 cities (Bombay, Madras, Hyderabad and Calcutta) as the major emission sources. This exercise is nearly impossible to do based on realistic emissions of "real aerosols", because sources are numerous and aerosols cannot be tagged to their sources. Our objective is to determine the origin of the aerosol which makes up the plume observed by LIDAR on 7 March 1999 
(Pelon et al., 2002) and to assess whether the transport patterns leading to the simulated vertical structure of the plume are consistent with observations.

The main results can be summarized as follow:

- Downwind to the Western Ghats, over the Arabian Sea, a strong two-layered structure composed by the MABL and the land plume aloft, observed by LIDAR measurements, was realistically simulated with RAMS. According to tracer simulations, the aerosols observed in the land plume came from the southern Indian subcontinent. Within the MABL, pollutants came mainly from the southern Indian continent and Calcutta (below $6^{\circ} \mathrm{N}$ ), and to a lesser extent from Bombay and the northern Indian sub-continent (above $10^{\circ} \mathrm{N}$ ),

- As far as $600 \mathrm{~km}$ from the Indian coast, the vertical structure of the plume exhibits a sharp diurnal cycle, as shown with the tracer simulations. Closer to the coastline, ground-based LIDAR (aerosol extinction coefficient) and ship-borne Sun-photometer (AOD) measurements also evidenced a well marked diurnal cycle of aerosol optical properties. The observed and simulated diurnal cycles are in excellent agreement,

- The eastward shift of the subtropical high from central India to the Bay of Bengal leads to an increase in the tracer concentrations simulated over the Arabian Sea, in the region of intensive observations north of the Maldives, as transport pathways from Hyderabad and Madras were modified significantly,

- The nesting of a high horizontal resolution domain (5 km, with 39 vertical levels below $4000 \mathrm{~m} \mathrm{msl}$ ) allows for a better representation of local dynamics, sea breeze circulation, and therefore a noticeable improvement in the representation of the pollutants plume.

Future work will be focused on realistic simulations of the haze plume to compute (using Mie theory) the extinction and backscatter coefficient profiles based on simulated aerosol concentrations and distributions, and compare them with their LIDAR-derived counterparts. This shall be done on the high horizontal resolution domain $(5-\mathrm{km})$ rather than the $20-\mathrm{km}$ resolution domain.

Acknowledgements. This work was supported by funding of the Centre National de la Recherche Scientifique through the Programme National de Chimie Atmosphérique (PNCA) and the Programme Atmosphère et Océan à Moyenne Echelle (PATOM). Mystere 20 operations were supported by the European Space Agency (ESA). This work makes a large use of the RAMS model, which was developed under the support of the National Science Foundation (NSF) and the Army Research Office (ARO). Computer ressources were provided by CINES (Centre Informatique National de l'Enseignement Supérieur) project amp2107. The authors also wish to thank the computer team of the Laboratoire de Météorologie Physique de l'Université Blaise Pascal (France):
A. M. Lanquette, P. Cacault and F. Besserve. Finally, A. Jayaraman is acknowledged for permission to use the ship-borne sun-photometer data. The authors would also like to thank the three referees for their numerous and fruitfull comments that lead to a significant improvement of the paper.

Edited by: A. Stohl

\section{References}

Angevine, W. M., Trainer, M. T., McKeen, S. A., and Berkowitz, C. M.: Mesoscale meteorology of the New England coast, Gulf of Maine, and Nova Scotia: Overview, J. Geophys. Res., 101, 28 893-28 901, 1996.

Audiffren, N., Buisson, E., Cautenet, S., and Chaumerliac, N.: Photolytic impact of a stratocumulus cloud layer upon the chemistry of an offshore advected plume of pollutants during the NARE 1993 intensive experiment: a numerical study, Atmos. Res., 70 , 89-108, 2004.

Cautenet, S., Poulet, D., Delon, C., Delmas, R., Grégoire, J. M., Pereira, J. M., Cherchali, S., Amram, O., and Flouzat, G.: Simulation of carbon monooxide redistribution over Central Africa during biomass burning (Experiment for Regional Sources and Sinks of Oxidants (EXPRESSO)), J. Geophys. Res., 104, 30 641-30 657, 1999.

Chazette, P.: The monsoon aerosols extinction properties at Goa during INDOEX as measured with lidar, J. Geophys. Res., 108, 4187, doi:10.1029/2002JD002074,2003.

Clark, T. L. and Farley, R. D.: Severe downslope windstorm calculations in two and three spatial dimensions using anelastic interactive grid nesting: A possible mechanism for gustiness, J. Atmos. Sci., 41, 329-350, 1984.

Cantrell, W., Shaw, G., Cass, G., Chowdhury, Z., Hughes, L., Prather, K., Guazzotti, S., and Coffee, K.: Closure between aerosol particles and cloud condensation nuclei at Kaashidhoo Climate Observatory, J. Geophys. Res., 106, 28711-28718, 2001.

Cantrell, W., Shaw, G., Leck, C., Granat, L., and Cachier, H.: Relationships between cloud condensation nuclei spectra and aerosol particles on a south-north transect of the Indian Ocean, J. Geophys. Res., 105, 15313-15 320, 2000.

Cotton, W. A., Pielke, R. A., Walko, R. L., Liston, G. E., Tremback, C. J., Jiang, H., McAnelly, R. L., Harrington, J. Y., Nicholls, M. E., Carrio, G. G., and McFadden, J. P.: RAMS 2001: Current status and future directions, Meteorol. Atmos. Phys., 82, 5-29, 2003.

De Reus, M., Krejci, R., Williams, J., Fischer, H., Scheele, R., and Ström, J.: Vertical and horizontal distributions of the aerosol number concentration and size distribution over the northern Indian Ocean, J. Geophys. Res., 106, 28 626-28 641, 2001.

Désalmand, F., Szantai, A., Picon, L., and Desbois, M.: Systematic observation of westward propagating cloud bands over the Arabian Sea during Indian Ocean Experiment (INDOEX) from Meteosat-5 data, J. Geophys. Res., 108, 8004, doi:10.1029/2002JD002934, 2003.

Draxler, R. R. and Hess, G. D.: An overview of the Hysplit_4 modeling system for trajectories, dispersion, and deposition, Aust. Met. Mag., 47, 295-308, 1998. 
Edy, J. and Cautenet, S.: Biomass burning : local and regional redistributions, Air Pollution Modeling and its application, Plenum Press, New-York, 63-69, 1998.

Ethé, C., Basdevant, C., Sadourny, R., Appu, K. S., Harenduprakash, L., Sarode, P. R., and Viswanathan, G.: Air mass motion, temperature, and humidity over the Arabian Sea and western Indian Ocean during the INDOEX intensive phase, as obtained from a set of superpressure drifting balloons, J. Geophys. Res., 107, 8023, doi:10.1029/2001JD001120, 2002.

Feingold, G., Walko, R. L., Stevens, B., and Cotton, W. R.: Simulation of marine stratocumulus using a new microphysical parameterization scheme, Atmos. Res., 47-48, 505-528, 1998.

Franke, K., Ansmann, A., Müller, D., Althausen, D., Venkataraman, C., Reddy, M. S., Wagner, F., and Scheele, R.: Optical properties of the Indo-Asian haze layer over the tropical Indian Ocean, J. Geophys. Res., 108, 8633, doi:10.1029/2002JD002473, 2003.

Hill, G. E.: Factors controlling the size and spacing of cumulus clouds as revealed by numerical experiments, J. Atmos. Sci., 31, 646-673, 1974.

Huebert, B. J., Bates, T., Russell, P. B., Shi, G., Kim, Y. J., Kawamura, K., Carmichael, G., and Nakajima, T.: An overview of ACE-Asia: Strategies for quantifying the relationships between Asian aerosols and their climatic impacts, J. Geophys. Res., 108, 8633, 10.1029/2003JD003550, 2003.

Krishnamurti, T. N., Jha, B., Prospero, J., Jayaraman, A., and Ramanathan, V.: Aerosol and pollutant transport and their impact on radiative forcing over the tropical Indian Ocean during the January-February 1996 pre-INDOEX cruise, Tellus B, 50, 521542, 1998.

Kuo, H. L.: A theory of parameterization of cumulus convection, J. Atmos. Sci., 22, 40-43, 1965.

Lelieveld, J., Crutzen, P. J., Ramanathan, V., Andrea, M. O., Brennikmeijer, C. A. M., Campos, T., Cass, G. R., Dickerson, R., Fischer, H., De Gouw, J. A., Hansel, A., Jefferson, A., Kley, D., De Laat, A. T. J., Lal, S., Lawrence, M. G., Lobert, J. M., MayolBracero, O. L., Mitra, A. P., Novakov, T., Oltmans, S. J., Prather, K. A., Rodhe, H., Scheeren, H. A., Sikka, D., and Williams, J.: The Indian Ocean Experiment : Widespread air pollution from South and South East Asia, Science, 292, 1031-1036, 2001.

Léon, J.-F., Chazette, P., Dulac, F., Pelon, J., Flamant, C., Bonazzola, M., Foret, G., Alfaro, S., Cachier, H., Cautenet, S., Hamonou, E., Gaudichet, A., Gomes, L., Rajot, J.-L., Lavenu, F., Inamdar, S. R., Sarode, P. R., and Kadadevarmath, J. S.: Largescale advection of continental aerosols during INDOEX, J. Geophys. Res., 106, 28 427-28 439, 2001.

Léon, J.-F., Tanré, D., Pelon, J., Dulac, F., and Randriamiarisoa, H.: Aerosol direct radiative impact over the INDOEX area based on passive and active remote sensing, J. Geophys. Res., 107, 8006, doi:10.1029/2000JD000116, 2002.

Lilly, D. K.: On the numerical simulation of buoyant convection, Tellus, 14, 148-172, 1962.

Lobert, J. M. and Harris, J. M.: Trace gas and air mass origin at Kaashidhoo, Indian Ocean, J. Geophys. Res., 107, 10.1029/2001JD000731, 2002.

Lohmann, U. and Feichter, J.: Can the direct and semi-direct aerosol effect compete with the indirect effect on a global scale?, Geophys. Res. Lett., 28, 159-161, 2001.

Lyons, W. A., Tremback, C. J., and Pielke, R. A.: Applications of the regional atmospheric systems (RAMS) to provide input to photochemical grid models for the lake Michigan ozone study (LMOS), J. Appl. Meteor., 34, 1762-1785, 1995.

Lyons, W. A., Pielke, R. A., Tremback, C. J., Walko, R. L., Moon, D. A., and Keen, C. S.: Modeling impacts of mesoscale vertical motions upon coastal zone air pollution dispersion, Atmos. Env., 29, 283-301, 1995.

Mahapatra, A. S. and Michel, C. P.: Biofuel consumption, deforestation, and farm level tree growing in rural India, Biomass bioenergy, 17, 291-303, 1999.

Manghnani, V., Raman, S., Nyogi, D., Parameswara, V., Morrison, J., Ramana, S. V., and Raju, J.: Marine boundary-layer variability over the Indian Ocean during INDOEX (1998), Boundary Layer Meteorol., 97, 411-430, 2000.

Millan, M. M., Salvador, R., Mantilla, E., and Kallos, G.: Photooxidant dynamics in the smtag307 Mediterranean basin in summer: Results from European research projects, J. Geophys. Res., 102, 8811-8823, 1997.

Minvielle, F., Cautenet, G., Andreae, M. O., Lasserre, F., Foret, G., Cautenet, S., Léon, J.-F., Mayol-Bracero, O. L., Gabriel, R., Chazette, P., and Roca, R.: Modelling the transport of aerosols during Indoex 1999 and comparison with experimental data - 1: carbonaceous aerosol distribution, Atmos. Environ., 38, 18111822, 2004a.

Minvielle, F., Cautenet, G., Lasserre, F., Foret, G., Cautenet, S., Léon, J.-F., Andreae, M. O., Mayol-Bracero, O. L., Gabriel, R., Chazette, P., and Roca, R.: Modelling the transport of aerosols during Indoex 1999 and comparison with experimental data - 2: Continental aerosolsand their optical depth, Atmos. Environ., 38, 1823-1837, 2004b.

Mohanty, U., Niyogi, D., Raman, S., and Sarkar, A.: Numerical simulation of land-air-sea interactions over the Indian ocean during the northeasterly Monsoon during INDOEX, Curr. Sci., 80, 60-68, 2001.

Olivier, J. G. J., Bouwman, A. F., Van der Mass, C. W. M., Berdowski, J. J. M., Veldt, C., Bloos, J. P. J., Visschedijk, A. J. H., Zandveld, P. Y. J., and Haverlag, J. L.: Description of EDGAR version 2.0. A description of global emission inventories of greenhouse gases and ozone-depleting substances for all anthropogenic and most natural sources on a per country basis and on $1 * 1$ degree grid, RIVM/TNO report, December 1996, RIVM, Bilthoven, RIVM report nr. 771060 002, 1996.

Pelon, J., Flamant, C., Chazette, P., Léon, J.-F., Tanre, D., Sicard, M., and Satheesh, S. K.: Characterization of aerosol spatial distribution and optical properties over the Indian Ocean from airborne LIDAR and radiometry during INDOEX'99, J. Geophys.Res., 107, 8029, doi:10.1029/2001JD000402, 2002.

Raes, F., Bates, T., McGovern, F. M., and Van Liederkerte, M.: The second Aerosol Characterization Experiment (ACE-2) : general overview and main results, Tellus, 52B, 111-126, 2000.

Rajeev, K., Ramanathan, V., and Meywerk, J.: Regional aerosol distribution and its long-range transport over the Indian Ocean, J. Geophys. Res., 105, 2029-2043, 2000.

Raman, S., Devdutta, D., Niyogi, S., Simpson, M., and Pelon, J.: Dynamic of the elevated land plume over the Arabian Sea and the Northern Indian Ocean during northeasterly monsoons and during the Indian Ocean Experiment (INDOEX), Geophys. Res. Lett., 29, doi:10.1029/2001GL014193, 2002.

Ramanathan, V., Chung, C., Clarke, A., Coakley, J., Collins, W., Conant, W., Dulac, F., Heintzenberg, J., Heymsfield, A., Hol- 
ben, B., Howell, S., Crutzen, P., Hudson, J., Jayaraman, A., Kiehl, J., Krishnamurti, T., Lubin, D., McFarquhar, G., Novakov, T., Ogren, J., Podgorny, I., Prather, K., Lelieveld, J., Priestley, K., Prospero, J., Quinn, P., Rajeev, K., Rasch, P., Rupert, S., Sadourny, R., Satheesh, S., Shaw, G., Sheridan, P., Mitra, A., Valero, F., Althausen, D., Anderson, J., Andreae, M., Cantrell, W., and Cass, G.: Indian Ocean Experiment: An integrated analysis of the climate forcing and effects of the great Indo-Asian haze, J. Geophys. Res., 106, 28 371-28 398, 2001.

Rasch, P. J., Collins, W. D., and Eaton, B.: Understanding the Indian Ocean Experiment (INDOEX) aerosol distributions with an aerosol assimilation, J. Geophys. Res., 106, 7337-7355, 2001.

Reddy, M. S., Boucher, O., Venkataraman, C., Verma, S., Léon, J.-F., Bellouin, N., and Pham, M.: General circulation model estimates of aerosol transport and radiative forcing during the Indian Ocean Experiment, J. Geophys. Res., 109, D16205, doi:10.1029/2004JD004557, 2004.

Reiner, T., Sprung, D., Jost, C., Gabriel, R., Mayol-Bracero, O. L., Andreae, M. O., Campos, T. L., and Shetter, R. E.: Chemical characterization of pollution layers over the tropical Indian Ocean: Signatures of emissions from biomass and fossil fuel burning, J. Geophys. Res, 106, 28 497-28 510, 2001.

Roswintiarti, O., Raman, S., Mohanty, U. C., and Niyogi, D.: Application of three-dimensional triple nested mesoscale model for assessing the transport and boundary layer variability over the Indian Ocean during INDOEX, Curr. Sci., 80, 69-76, 2001.

Russell, P. B., Hobbs, P. V., and Stowe, L. L.: Aerosol and radiative effects in the United States east coast haze plume: An overview of the tropospheric Aerosol radiative Forcing Observational experiment (TARFOX), J. Geophys. Res., 104, 2213-2222, 1999.

Sinha, C. S., Sinha, S., and Josh, V.: Energy use in the rural areas of India: setting up a rural energy database, Biomass bioenergy, 14, 489-503, 1998.

Slinn, S. A. and Slinn, W. G. N.: Prediction for particle deposition on natural waters, Atmos. Env., 14, 1013-1016, 1980.

Smagorinsky, J.: General circulation experiments with the primitive equations, Mon. Wea. Rev., 91, 99-164, 1963.
Streets, D. G. and Waldhoff, S. T.: Greenhouse-gas emission from biofuel combustion in Asia, Energy, 24, 841-855, 1999.

Taghavi, M., Cautenet, S., and Foret, G.: Simulation of ozone production in a complex circulation region using nested grids, Atmos. Chem. Phys., 4, 825-838, 2004.

Taghavi, M., Cautenet, S., and Arteta, J.: Impact of an high resolution emission inventory on modeling accuracy, Atmos. Res., 74/1-4, 65-88, 2005.

Tremback, C. J.: Numerical simulation of a mesoscale convective complex: Model development and numerical results, $\mathrm{PhD}$ thesis, Colorado State University, 247 pp, 1990.

Twohy, C. H., Hudson, J. G., Yum, S.-S., Anderson, J. R., Durlak, S. K., and Baumgardner, D.: Characteristics of cloud-nucleating aerosols in the Indian Ocean region, J. Geophys. Res., 106, 28 699-28 710, 2001.

Verver, G. H. L., Sikka, D. R., Lobert, J. M., Stossmeister, G., and Zachariasse, M.: Overview of the meteorological conditions and atmospheric transport processes during INDOEX 1999, J. Geophys. Res., 106, 28 399-28 413, 2001.

Walko, R. L., Tremback, C. J., Pielke, R. A., and Cotton, W. R.: An interactive nesting algorithm for stretched grids and variable nesting ratios, J. Appl. Meteor., 34, 994-999, 1995.

Walko, R., Band, L. L. E., Baron, J., Kittel, T. G., Lammers, R., Lee, T. J., Ojima, D., Pielke Sr., R. A., Taylor, C., Tague, C., Tremback, C. J., and Vidale, P. L.: Coupled atmosphere-biophysicshydrology models for environmental modelling, J. Appl. Meteor., 39, 931-944, 2000.

Wang, Y. X., Elroy, M. B., Jacob, D. J., and Yantosca, R. M.: A nested grid formulation for chemical transport over Asia: Applications to CO, J. Geophys. Res., 109, D22307, doi:10.1029/2004JD005237, 2004.

Welton, E. J., Voss, K. J., Quinn, P. K., Flatau, P. J., Markowicz, K., Campbell, J. R., Spinhirne, J. D., Gordon, H. R.: Measurements of aerosol vertical profiles and optical properties during INDOEX 1999 using micropulse lidars, J. Geophys. Res., 107, 8019, doi:10.1029/2000JD000038, 2002. 